\title{
A reassessment of the iron isotope composition of the Moon and its implications for accretion and differentiation of terrestrial planets
}

\author{
Franck Poitrasson $^{\mathrm{a}, *}$, Thomas Zambardi ${ }^{\mathrm{a}}$, Tomas Magna ${ }^{\mathrm{b}}$ and Clive R. Neal ${ }^{\mathrm{c}}$ \\ ${ }^{\mathrm{a}}$ Laboratoire Géosciences Environnement Toulouse,
} Centre National de la Recherche Scientifique UMR 5563 - UPS - IRD - CNES, 14-16, avenue Edouard Belin, 31400 Toulouse, France.

${ }^{\mathrm{b}}$ Czech Geological Survey, Klarov 3, CZ-11821 Prague 1, Czech Republic.

${ }^{\mathrm{c}}$ Department of Civil and Environmental Engineering and Earth Sciences, University of Notre Dame, 156 Fitzpatrick Hall, Notre Dame, IN 46556, USA.

*Corresponding author; e_mail: Franck.Poitrasson@get.omp.eu

Submitted to Geochimica et Cosmochimica Acta

Second revised version $20^{\text {th }}$ September 2019 
The Fe isotope composition of planetary bodies may provide constraints on their accretion modes and/or differentiation processes, but to do so, the Fe isotope systematics of key planetary reservoirs needs to be determined. To investigate this for the Moon, we measured the $\mathrm{Fe}$ isotope compositions for a suite of 33 bulk lunar mare basalts and highland rocks. Combined with published data, a compendium of 73 different lunar bulk rocks reveals a statistically significant Fe isotope difference between low-Ti and high-Ti mare basalts, yielding average $\delta^{57} \mathrm{Fe}=0.127 \pm 0.012 \%$ o $(2 \mathrm{SE} ; \mathrm{n}=27)$ and $\delta^{57} \mathrm{Fe}=0.274 \pm 0.020 \%$ ( $2 \mathrm{SE} ; \mathrm{n}$ =25), respectively, relative to the IRMM-14 isotopic reference material. As lunar basalts are thought to reflect the Fe isotope composition of their respective mantle sources, the estimated relative proportion of the low-Ti and high-Ti source mantle suggests that the lunar upper mantle $\delta^{57} \mathrm{Fe}$ value should be close to $0.142 \pm 0.026 \%$. Whilst the composition of highland rocks (ferroan anorthosites and Mg-suite rocks) should provide a more global view of the Moon, the calculation of the mean $\delta^{57} \mathrm{Fe}$ value of 15 available highland rock analyses yields $\delta^{57} \mathrm{Fe}=0.078 \pm 0.124 \%$. Such a value is not defined precisely enough to be of critical use for comparative planetology. Ferroan anorthosites and Mg-suite rocks also give unresolvable means. It appears that $\mathrm{Fe}$ isotope heterogeneity among the lunar highland rocks is caused by non-representatively too small sample aliquots of coarse-grained rocks. It can also be the result of mixed lithologies for some. When the (kinetic) effect of olivine tending towards low $\delta^{57} \mathrm{Fe}$ and feldspar with predominantly high $\delta^{57} \mathrm{Fe}$ is cancelled, a more precise $\delta^{57} \mathrm{Fe}$ value of $0.094 \pm 0.035 \%$ is calculated. It is indistinguishable from the mean $\delta^{57} \mathrm{Fe}$ of impact melts and is also similar to the upper lunar mantle estimate obtained from mare basalts. Collectively, this newly determined Fe isotope composition of the bulk Moon is indistinguishable from that of the Earth, and heavier than those reported for other planetary bodies. This planetary isotope 
relationship is only observed for silicon given the currently available mass-dependent stable isotope database. Because both iron and silicon reside in the Earth's metallic core in significant quantities, this may point to the involvement of metallic cores of the Earth and Moon in the interplanetary $\mathrm{Fe}$ and $\mathrm{Si}$ isotope fractionation. Rather than via high-pressure metal-silicate fractionation at the core-mantle boundary, this would more likely be achieved by partial vaporization of the liquid outer metallic core in the aftermath of a Moon-forming giant impact.

Keywords: iron isotopes; Moon; mare basalts; anorthosites; Mg-suite; highland rocks.

\section{Introduction}

Investigation of the stable isotope compositions of planetary bodies other than the Earth has been facilitated through the return of lunar samples by the Apollo missions, as well as the recognition of Martian meteorites in existing collections (McSween Jr et al., 1979), and meteorites coming from the differentiated asteroid Vesta (Consolmagno and Drake, 1977). Following pioneering studies of oxygen, silicon and potassium isotope compositions (e.g. Clayton et al., 1971; Clayton and Mayeda, 1983; Molini-Velsko et al., 1986; Humayun and Clayton, 1995), the past 15 years witnessed rapid improvements in our knowledge of stable isotope compositions of a number of major and trace elements in lunar and other planetary bodies (e.g., Mg: (Wiechert and Halliday, 2007; Bourdon et al., 2010; Teng et al., 2010; Hin et al., 2017); Si: (Georg et al., 2007; Fitoussi et al., 2009; Ziegler et al., 2010; Zambardi et al., 2013); Ca: (Simon and DePaolo, 2010); Fe: (Poitrasson et al., 2004; Weyer et al., 2005; Schoenberg and von Blanckenburg, 2006; Wang et al., 2015; Sossi and Moynier, 2017); Zn: (Moynier et al., 2006; Paniello et al., 2012; Kato et al., 2015). These results were sometimes 
controversial, either due to analytical difficulties and/or the use of older generation of mass spectrometers, less precise and accurate (e.g., Mg: (Wiechert and Halliday, 2007; Bourdon et al., 2010; Chakrabarti and Jacobsen, 2010; Teng et al., 2010); Si: (Georg et al., 2007; Fitoussi et al., 2009; Savage et al., 2010; Ziegler et al., 2010; Zambardi et al., 2013), or resulting from different interpretations of mass-dependent stable isotope variations (e.g., Fe: (Poitrasson et al., 2004; Weyer et al., 2005; Schoenberg and von Blanckenburg, 2006; Beard and Johnson, 2007; Poitrasson, 2007; Weyer et al., 2007; Poitrasson, 2009; Polyakov, 2009; Rustad and Yin, 2009; Wang et al., 2015; Elardo and Shahar, 2017; Elardo et al., 2019). For iron, this resulted in debates on estimating the bulk stable isotope composition of planets (see Fig. 1, for the Earth and the Moon). However, the interplanetary, mass dependent stable isotope variations hold great promise in unraveling early Solar System processes, such as planetary accretion mechanisms or mantle-core differentiation (Poitrasson et al., 2004; Georg et al., 2007; Polyakov, 2009).

Ideally, these stable isotope tracers should be little affected by common geological processes to allow easy interplanetary comparison (Humayun and Clayton, 1995). However, for those stable isotopes affected by processes such as fractional crystallization or element diffusion in solids, their fractionation mechanisms should be well understood and fully quantified to be useful for planet formation studies. Unfortunately, this is not yet the case for many of the elements under consideration. Beyond general rules common to all stable isotopes, such as the effect of temperature on the magnitude of isotopic fractionation or the stiffness of inter-atomic bonds (e.g. Schauble, 2004), initial studies have shown that elements such as $\mathrm{Fe}, \mathrm{Mg}$ or $\mathrm{O}$ will not fractionate in the same way because they are located in different crystallographic coordination configurations or may be differently affected by redox processes. For this reason, it is important to determine and understand the systematics of the stable isotope fractionation during geological processes for all elements of interest. 
Among these, iron has attracted considerable attention given its importance and large

101 abundances in terrestrial planets, and the discovery of different planetary Fe isotope signatures (Poitrasson et al., 2004). However, with the expanding database, more complexities

103 than originally anticipated have been highlighted. For example, Liu et al. (2010) clearly

104 showed that there is a difference in the Fe isotope composition of lunar low-Ti and high-Ti

105 mare basalts that may directly mirror that of their respective mantle sources. This supports the

106 observations of Snyder et al. (1992) and Beard et al. (1998) who implied distinct mantle 107 sources of low-Ti and high-Ti mare basalts on the basis of petrogenetic modeling and 108 radiogenic isotope systematics, respectively. If true, this may eventually lead to a different 109 estimate for the bulk lunar Fe isotope composition. This finding is of notable importance as it 110 may provide a test for interplanetary $\mathrm{Fe}$ isotope variations imparted by either mantle-core 111 differentiation or partial vaporization in the aftermath of a Moon-forming giant impact 112 (Poitrasson, 2009).

113 In order to provide new constraints on $\mathrm{Fe}$ isotope fractionation during magmatic 114 evolution of the lunar magma ocean, we have determined the Fe isotope composition in a 115 suite of mare basalts and highland rocks. This new data set should enable a better evaluation 116 of potential differences between various lunar reservoirs and their significance in creating 117 bulk planetary signatures previously debated in the literature (Poitrasson et al., 2004; Weyer 118 et al., 2005; Beard and Johnson, 2007; Poitrasson, 2007; Weyer et al., 2007; Weyer and 119 Ionov, 2007; Liu et al., 2010; Wang et al., 2015; Elardo and Shahar, 2017; Sossi and Moynier, 120 2017; Elardo et al., 2019). Furthermore, the new Fe isotope data for several specimens were 121 collected in order to (i) verify earlier Fe isotope determinations by means of low mass 122 resolution MC-ICP-MS (Wiesli et al., 2003; Poitrasson et al., 2004), and (ii) constrain 123 potential sample heterogeneity problems (e.g., for olivine-normative basalt 15555). 


\section{Samples}

126

127

128

129

130

131

132

133

134

135

136

The samples were selected to reflect a wide range in petrological and geochemical types (Neal and Taylor, 1992; Warren, 1993; Papike et al., 1998; Neal, 2001; Meyer, 2011), as well as in their location on the Moon as sampled by the Apollo missions. Nine low-Ti and 12 highTi mare basalts, one KREEP basalt and one KREEP-rich impact melt, five ferroan anorthosites, two Mg-suite norites, one Mg-suite troctolite, one dunite, and one Mg-suite noritic anorthosite were analyzed. Only pristine highland rocks were selected for the new analyses reported in the present work according to criteria given in Warren (1993) defined on the basis of siderophile element contents and textural characteristics. This is important when considering that meteorite bombardment affects Fe isotope signatures on the lunar surface (Wiesli et al., 2003; Moynier et al., 2006; Poitrasson, 2007). These new data are compared to all previously published bulk lunar rock Fe isotope determinations, making up a Fe isotope database of 73 lunar rock samples. Meteorites of lunar origin (see their Fe isotope data in Wang et al., 2015) were not included in this compilation. This is due to an uncertain location of their origin on the Moon, strong shock modification and potential weathering on the Earth's surface. Most lunar meteorites were recovered from hot deserts and it has previously been shown that weathering under these conditions can significantly affect the Fe isotope signatures of bulk meteorites (Saunier et al., 2010).

\section{Methods}

Between 3 and $30 \mathrm{mg}$ of bulk-rock powder prepared from 0.1 to one gram of the original sample chip allocation were digested (See Table 1). Samples processed at GETCNRS, Toulouse were dissolved with a mixture of concentrated $\mathrm{HF}-\mathrm{HNO}_{3}-\mathrm{HCl}$ in closed 
high-pressure Teflon vessels in an oven at $135^{\circ} \mathrm{C}$ for 6 days. For samples processed at the

151 University of Lausanne, the same acid mixture was used and beakers were placed on a

152 hotplate at $120^{\circ} \mathrm{C}$ for 3 days. The resulting solutions were subsequently evaporated to dryness

153 and re-dissolved in $6 \mathrm{M} \mathrm{HCl}$ on a hotplate at $120^{\circ} \mathrm{C}$ for 48 hours. Dried residues were

154 thereafter dissolved using $6 \mathrm{M} \mathrm{HCl}$ prior to Fe purification by conventional anion-exchange

155 chromatography following established analytical protocols (Poitrasson et al., 2004, 2005).

156 The total procedural blanks were between 3 and $7 \mathrm{ng}$, which is more than three orders of

157 magnitude lower than Fe levels in samples and is thus considered negligible. Iron isotope

158 compositions were determined using a Neptune (ThermoFisher Scientific, Bremen, Germany)

159 high mass resolution multiple-collector inductively-coupled-plasma mass spectrometer (MC-

160 ICP-MS) housed at CNRS Toulouse, following the procedures detailed in Poitrasson and

161 Freydier (2005), which included mass bias correction of the purified Fe samples by Ni

162 doping. This approach accurately corrects for mass bias shifts caused by residual matrix

163 effects and results in a superior reliability of the measurements over the conventional

164 standard-sample bracketing method (see Poitrasson and Freydier, 2005).

165 The new Fe isotope compositions are reported in Table 1 using the standard delta 166 notation, in per mil (\%), relative to the European isotopic IRMM-14 reference material.

167 Analytical reproducibility was estimated on the basis of 80 analyses of an in-house hematite 168 standard from Milhas, Pyrénées (sometimes referred to in the literature as "ETH hematite 169 standard"), conducted over 3 years and in the same analytical sequences as the sample 170 analyses reported in Table 1. Every sample was typically analyzed six times; the long term 171 reproducibility of such pooled measurements can be estimated on the basis of the hematite 172 reference material analyses pooled in groups of six individual measurements. This yielded $173 \delta^{57} \mathrm{Fe}=0.758 \pm 0.067 \%$ and $\delta^{56} \mathrm{Fe}=0.511 \pm 0.046 \%$ (2SD). Additionally, BHVO-2 and JB-2

174 basalt reference materials analyzed during this study yielded $\delta^{57} \mathrm{Fe}$ of $0.182 \pm 0.062 \%$ and 
$1750.095 \pm 0.082 \%$ (2SD), respectively, in good agreement with literature values (Weyer et al., 176 2005; Craddock and Dauphas, 2011).

177 In the reminder of this paper, the uncertainties of the sample set mean values are 178 calculated as two standard errors of the mean (2SE) rather than two standard deviations (2SD)

179 in order to indicate how well the mean values are constrained rather than to give a measure of

180 the spread of a set of individual measurements around the mean (see e.g. Miller and Miller,

181 1993). The $2 \mathrm{SE}$ calculation involves the use of the t-correcting factor that takes into account 182 the number of samples used in the calculation (Platzner, 1997). Furthermore, these 2SE 183 uncertainties represent a direct proxy of the Student's t-test (e.g., Poitrasson et al., 2004, 184 2005; Zambardi et al., 2013). All literature data have been recalculated in this way to be 185 mutually comparable. However, irrespective of whether calculated as either 2SE or 2SD, it is 186 important to note that these estimated uncertainties only include analytical random errors but not systematic ones potentially associated with analytical or sampling biases.

\section{Results and comparison with previous data}

Thirty three new Fe isotope analyses of bulk lunar rock samples are listed in Table 1.

192 The low-Ti basalts and high-Ti basalts show well-defined but mutually distinct $\delta^{57} \mathrm{Fe}$ ranges

193 from $0.043 \pm 0.023 \%$ to $0.154 \pm 0.071 \%$ and from $0.167 \pm 0.118 \%$ o $0.354 \pm 0.118 \%$, 194 respectively. The new Fe isotope data for low-Ti mare basalts confirm previous observations 195 of homogeneous $\delta^{57} \mathrm{Fe}$ systematics, similar to Earth (Liu et al., 2010). Two high-K mare 196 basalts $(10049,10057)$ from the Apollo 11 high-Ti group show systematically lower $\delta^{57} \mathrm{Fe}$ 197 values $(\leq 0.187 \%$ ) compared with the rest of the Apollo 11 suite $(\geq 0.290 \%)$ and the entire 198 Apollo 17 suite $\left(\geq 0.213 \%\right.$ ). KREEP basalt 15386 has $\delta^{57} \mathrm{Fe}=0.18 \pm 0.07 \%$, intermediate 199 between low-Ti and high-Ti mare basalts. 
The new highland data reveal a bulk rock $\delta^{57} \mathrm{Fe}$ range from $-0.73 \pm 0.06 \%$ o to $0.50 \pm$ $0.06 \%$ (Table 1 ). This $>1.2 \%$ variation is surprisingly large for igneous rocks, and is only approached by terrestrial mantle peridotites (see Williams et al., 2005; Weyer and Ionov, 2007; Zhao et al., 2010; Poitrasson et al., 2013). Ferroan anorthosites span a $\delta^{57} \mathrm{Fe}$ range from 204 $-0.39 \pm 0.05 \%$ o to $0.50 \pm 0.06 \%$ although the negative $\delta^{57} \mathrm{Fe}$ datum has only been measured 205 for sample 60025. Two Mg-suite norites 15455 and 77215 exhibit $\delta^{57} \mathrm{Fe}$ values of $0.07 \pm$ 206 $0.02 \%$ and $0.05 \pm 0.05 \%$, respectively. Dunite 72415 yielded an extremely light $\delta^{57} \mathrm{Fe}$ value of $-0.73 \pm 0.06 \%$ (Table 1 and Fig. 2). Mg-suite troctolite 76335 has $\delta^{57} \mathrm{Fe}=-0.01 \pm 0.06 \%$. The two most negative values, from dunite 72415 and Fe-anorthosite 60025, were fully duplicated by new sample powder dissolutions, iron purifications by ion exchange chromatography and MC-ICP-MS measurements. In both cases, identical results were obtained so the figures reported in Table 1 represent the average of these duplicate 212 determinations. The KREEP-rich basaltic impact melt 14310 yielded a $\delta^{57} \mathrm{Fe}=0.13 \pm 0.13 \%$, similar to the value for pristine KREEP basalt 15386.

Some new analyses reported in Table 1 represent replicate data obtained on a new sample aliquot from the same Apollo rock compared to previously published values. Among 216 these, the new $\delta^{57} \mathrm{Fe}$ values for several samples (low-Ti mare basalts 12045 and 14053, high217 Ti mare basalts 10057, 70135 and 74275, KREEP-rich basaltic impact melt 14310, KREEP 218 basalt 15386, Mg-suite norite 15455, anorthosites 15455 and 62255) are indistinguishable 219 within uncertainties from those reported elsewhere (Wiesli et al., 2003; Poitrasson et al., 220 2004; Weyer et al., 2005). In contrast, new $\delta^{57} \mathrm{Fe}$ values for Mg-suite norite 77215 are 221 significantly lower than the value published by Poitrasson et al. (2004), whereas the new $222 \delta^{57} \mathrm{Fe}$ value for high-Ti basalt 10003 is higher than that of Sossi and Moynier (2017). A full 223 replicate analysis of high-alumina basalt 14053 (Table 1), for which different chips were 224 obtained in two different CAPTEM allocations (to CRN and FP), have indistinguishable Fe 
225 isotope compositions; yet the recent $\delta^{57} \mathrm{Fe}$ value by Sossi and Moynier (2017) is higher. This 226 could be caused by modest sample heterogeneity because high-Al basalt 14053 was subject to 227 thermal metamorphism in an impact melt sheet that caused native Fe to form in the outer 228 portion of the sample (Taylor et al., 2004). The new measurement of Mg-suite dunite 72415 229 yielded $\delta^{57} \mathrm{Fe}=-0.73 \pm 0.06 \%$, which is statistically significantly lighter than the already 230 very light previously reported values of $-0.53 \pm 0.03 \%$ (Wang et al., 2015), and $-0.60 \pm$ $2310.05 \%$ (Sossi and Moynier, 2017). Therefore, the very light Fe isotope signature of 72415 is 232 confirmed (Table 1 and Fig. 2).

Data reported for olivine-normative low-Ti basalt 15555 by Poitrasson et al. (2004) and Weyer et al. (2005) were differing by more than $0.16 \%$, and therefore well outside the quoted analytical uncertainties. This possibly results from the medium- to coarse-grained nature of this rock with variable olivine modal contents between different rock chips (Ryder, 1985). Our new Fe isotope determination for basalt 15555 yields a $\delta^{57} \mathrm{Fe}$ value intermediate to those published elsewhere (Poitrasson et al., 2004; Weyer et al., 2005; Liu et al., 2010; Wang et al., 2015; Sossi and Moynier, 2017). There are no published $\delta^{57} \mathrm{Fe}$ values yet of olivines from low-Ti basalt 15555 . Taking the $\delta^{57} \mathrm{Fe}=-0.117 \%$ or for olivine from low-Ti ilmenite basalt 12045 (Poitrasson et al., 2004) and assuming that the variable modal content of olivine in 15555 will not be accompanied by distinctive olivine Fe isotope compositions, we can compute a bulk rock $\delta^{57} \mathrm{Fe}$ ranging from 0.141 to $0.101 \%$ with olivine modal content varying respectively from 5\% to $20 \%$, depending on the 15555 sample allocation (Meyer, 2011). This $0.040 \%$ range is four times smaller than the range of 15555 bulk rock values published so far, which is $0.164 \%$ from six different rock allocations (Table 1). Taking the other low-Ti basalt 247 (sample 12021) olivine value of 0.08\% published by Wang et al. (2015) would make the 248 range among calculated bulk rock $\delta^{57} \mathrm{Fe}$ values for 15555 even smaller since it is closer to the reported bulk rock values. This suggests that other causes than solely olivine modal contents 
250 are responsible for the scatter among the published bulk rock $\delta^{57} \mathrm{Fe}$ values for basalt 15555 .

251 As discussed below, it is likely that unrepresentative aliquot allocations of coarse-grained and 252 mineralogically heterogeneous rocks such as 15555 is the main reason for this discrepancy. 253 The most extreme discrepancy with previous results is observed for ferroan anorthosite 254 60025. The new $\delta^{57} \mathrm{Fe}$ result is $>0.6 \%$ lighter than the value reported in Poitrasson et al. 255 (2004). A full replicate of the entire analytical protocol at CNRS Toulouse yielded an 256 identical result confirming the reliability of the analytical and instrumental procedures. 257 Petrologic heterogeneity within 60025 with various modal content of felsic and mafic 258 minerals depending on the sample fragment has been previously documented (e.g. James et al., 1991; Torcivia and Neal, 2017, 2018). This will be discussed in more detail below.

\section{Discussion}

\subsection{The key role of the sample size for representative Fe isotope analysis}

The inter-laboratory comparison of $\mathrm{Fe}$ isotope measurement procedures on wellhomogenized silicate rock reference materials commonly shows good agreement (Beard and Johnson, 2006; Poitrasson, 2006, 2007; Craddock and Dauphas, 2011). Hence, the analytically significant $\delta^{57} \mathrm{Fe}$ differences between new data and published values for lunar samples $77215,10003,14053,15555,60025$ and 72415 appear to reflect sample heterogeneity rather than analytical issues. Literature data for high-Ti mare basalt 70035 also 270 yield discrepant $\delta^{57} \mathrm{Fe}$ values (Fig. 2 and Supplementary Table). Given that the entire 271 replicated lunar sample data were obtained on powder aliquots produced from different rock 272 chips, it is possible that for at least these seven lunar rocks, the sample mass used to prepare 273 the powders was too small to be representative of the bulk rock $\delta^{57} \mathrm{Fe}$ given the variable 274 mineral grain size. These sample sizes typically range from $\sim 50 \mathrm{mg}$ to $\sim 1 \mathrm{~g}$, but some studies 
report Fe isotope analyses based on the direct dissolution of rock chips of "a few milligrams"

276 size (Wang et al., 2015). For the smaller sample sizes, Fe isotope variations probably reflect

277 the relative differences in abundance of the major mineral phases sampled (e.g. olivine in 278 basalt 15555, Ryder, 1985), which may carry distinctly different Fe isotope signature 279 (Poitrasson et al., 2004; Craddock et al., 2010; Wang et al., 2015). This would translate into 280 rock chips used for the analyses having olivine modal contents well outside the range of 5 to $28120 \%$ reported for 15555 (Meyer, 2011). In contrast, the Fe isotope analysis of bulk terrestrial 282 rocks would be performed with an aliquot of powder typically produced from the crushing and homogenization of at least several hundred grams of rock (see general rock sample 284 preparation methods in Potts, 1987). Though often underestimated, such a sampling issue was 285 previously pointed out for lunar Apollo rocks. For example, trace and even major element 286 concentration heterogeneity issues were noted for basalt 15555 when comparing analyses 287 based on powders made from rock aliquots of less than 1g (Ryder and Steele, 1988; Ryder and Schuraytz, 2001). This was also reported to bias the oxygen isotope compositions of basalts 75075 and 15555 (Spicuzza et al., 2007; Liu et al., 2010), and, more recently, the 290 silicon isotope composition of ferroan anorthosites 65035 and 60015 (Poitrasson and 291 Zambardi, 2015), when powders were produced from rock chips weighing less than $\sim 100 \mathrm{mg}$ 292 (Armytage et al., 2012). Moreover, for basalt 15555, an anomalously light $\mathrm{Mg}$ isotope 293 signature reported recently (Sedaghatpour and Jacobsen, 2019), combined with significant $294 \mathrm{Fe}-\mathrm{Mg}$ inter-mineral diffusion affecting $\mathrm{Mg}$ isotope systematics in olivine crystals of 15555 295 (Richter et al., 2016), provide an additional clue for possible sample Fe isotope heterogeneity 296 issue (see Table 1).

Our new results (Table 1 and Fig. 2) reveal an extended range of Fe isotope 298 compositions for lunar bulk rock samples $(-0.73$ to $0.50 \%$ o $)$ relative to what has been published so far (Wiesli et al., 2003; Poitrasson et al., 2004; Weyer et al., 2005; Liu et al., 
2010; Wang et al., 2015; Sossi and Moynier, 2017) with the most extreme values observed among the highland rocks (Fig. 2 and Table 1). Most ferroan anorthosites show distinctly heavy $\mathrm{Fe}$ isotope composition $\left(\delta^{57} \mathrm{Fe}>0.18 \%\right.$ ), similar to high-Ti basalts (Figure 2 and see also Poitrasson, 2007), or even higher with ferroan anorthosite 15415 yielding $\delta^{57} \mathrm{Fe}=0.50 \%$ (This study). This is consistent with the results of $\mathrm{Fe}$ isotope investigations of mineral separates performed by Craddock et al. (2010) on a suite of low-Ti and high-Ti mare basalts, clearly identifying ilmenite and plagioclase as ${ }^{57} \mathrm{Fe}$-enriched phases.

Two different CAPTEM allocations of 60025 deviate by $>0.6 \%$ in $\delta^{57} \mathrm{Fe}$ (Table 1). Iron is predominantly hosted by pyroxene and olivine in lunar rocks (Papike et al., 1998) and if these phases are isotopically fractionated as is the case for mare basalts (Poitrasson et al., 2004; Craddock et al., 2010), an effect on the Fe isotope signature of bulk anorthosites may be expected since the occurrence of an isotopically fractionated Fe-rich mafic mineral phase may modify the $\delta^{57} \mathrm{Fe}$ values. These pilot studies on mineral separates from lunar basalts also indicated that plagioclase is isotopically heavier than coexisting olivine and pyroxene. This could indeed explain the heavy Fe isotope signature of anorthosites compared to some other mafic highland rocks. In the case of 60025, Poitrasson et al. (2004) reported Fe content of 0.50 wt. $\%$, whereas the analysis of the allocated sub-sample 60025,874 revealed 4.84 wt. $\%$ Fe, nearly one order of magnitude higher abundance (Supplementary Table). Such a composition approaches those of mafic portions of 60025 (Ryder, 1982; James et al., 1991; Meyer, 2011) and confirms the larger occurrence of olivine and pyroxene in our sample allocation, most probably leading to notably lower $\delta^{57} \mathrm{Fe}$ signature relative to the other $\delta^{57} \mathrm{Fe}$ measurements of 60025 and other anorthosites. In addition, Ryder (1982) concluded that systematic variations in the mineral chemistry of 60025 were probably a reflection that this sample was a mixture of closely related materials. Future work requires rigorous investigations by in situ isotopic work on anorthosite mineral phases (e.g., Oeser et al., 2015) 
to fully evaluate this. The influence of olivine is well illustrated at the bulk-rock scale with dunite 72415 having $\sim 93 \%$ modal olivine (Dymek et al., 1975) and with reported $\delta^{57} \mathrm{Fe}$ values ranging from -0.5 to $-0.73 \%$ depending on the rock chip analyzed (Table 1 and Fig. 2). Such isotopically light values in olivine could result from chemical diffusion-driven kinetic disequilibrium between olivine and the last melt olivine was in contact with (Wang et al., 2015). The implications of these findings are further discussed below.

\subsection{Iron isotope composition of different lunar reservoirs}

Bulk lunar samples may be grouped into four different sets given their petrologic characteristics (e.g., Papike et al., 1998): Low-Ti basalts, high-Ti basalts, highland rocks and impact melts. Nine new low-Ti basalts yield a mean $\delta^{57} \mathrm{Fe}=0.113 \pm 0.023 \%$ (2SE) and 12 new high-Ti basalts analyses give $\delta^{57} \mathrm{Fe}=0.273 \pm 0.039 \%$ (2SE). These values are indistinguishable from mean $\delta^{57} \mathrm{Fe}$ values of $0.118 \pm 0.028 \%$ o $(2 \mathrm{SE}, \mathrm{n}=10)$ and $0.291 \pm$ 0.051\% (2SE, $n=7$ ), reported by Liu et al. (2010) for low- and high-Ti basalts, respectively. It should be noted that our new data include a full replicate analysis of high-alumina basalt 14053 (Table 1) for which different chips were obtained in two different CAPTEM allocations. Given that these replicate analyses are indistinguishable within uncertainty, their mean value is used for the low-Ti basalt average $\delta^{57} \mathrm{Fe}$ reported above. The new data from this study together with previously published results by Wiesli et al. (2003), Poitrasson et al. (2004), Weyer et al. (2005), Liu et al. (2010), Wang et al. (2015) and Sossi and Moynier (2017) yield a cumulative mean $\delta^{57} \mathrm{Fe}_{\text {low-Ti }}=0.127 \pm 0.012 \%$ o $(2 \mathrm{SE}, \mathrm{n}=27$; Table 1$)$. For replicate analyses, the average $\delta^{57} \mathrm{Fe}$ of independent determinations is used to avoid overweighting of samples analyzed multiple times in the calculated mean. Using the same approach, we obtain a mean $\delta^{57} \mathrm{Fe}_{\text {high-Ti }}=0.274 \pm 0.020 \%$ o $(2 \mathrm{SE}, \mathrm{n}=25$; Table 1$)$. Our eleven 
new determinations of $\delta^{57} \mathrm{Fe}$ in highland rocks lead to a less well-defined mean because of the significant Fe isotope variations among the samples. With the literature data included, the mean $\delta^{57} \mathrm{Fe}_{\text {highland }}=0.078 \pm 0.124 \%$ o $(2 \mathrm{SE}, \mathrm{n}=15$; Table 1$)$ is calculated. Within this group,

353 Fe-anorthosites yield a mean $\delta^{57} \mathrm{Fe}$ composition of $0.192 \pm 0.207 \%$ o $(2 \mathrm{SE} ; \mathrm{n}=6)$ whereas a $354 \delta^{57} \mathrm{Fe}$ value of $0.002 \pm 0.179 \%$ o $(2 \mathrm{SE} ; \mathrm{n}=9)$ is obtained for the Mg-suite rocks. With literature 355 data included, impact melts yield a mean $\delta^{57} \mathrm{Fe}_{\text {impact }}=0.093 \pm 0.055 \%$ o $(2 \mathrm{SE}, \mathrm{n}=5)$.

The new data imply that the Fe isotope systematics of the Moon is more complex than 357 initially thought. As highlighted by Liu et al. (2010), low-Ti and high-Ti mare basalts possess 358 distinctive Fe isotope signatures (Fig. 2). With the new and published mare basalt data 359 included, a $t$-test allows us to reject the null hypothesis of a common origin of low-Ti and 360 high-Ti basalts with a level of confidence well above 99\% (See Supplementary Table). 361 Furthermore, the $t$-tests show that both the highland rocks and the impact melts have $\mathrm{Fe}$ 362 isotope composition indistinguishable from that of the low-Ti basalts, whereas their mean $363 \delta^{57} \mathrm{Fe}$ values are statistically different from that of high-Ti basalts with a degree of confidence 364 higher than 99\% (Supplementary Table). Hence, from the viewpoint of the observed $\mathrm{Fe}$ 365 isotope systematics, the different rock types may be arranged as two isotopically distinct 366 groups: a ${ }^{57} \mathrm{Fe}$-enriched end-member defined by high-Ti basalts, and a ${ }^{57} \mathrm{Fe}-$ depleted end367 member best defined by low-Ti basalts, but also including impact melts and highland rocks, 368 though the latter do not define a well-constrained mean $\delta^{57} \mathrm{Fe}$ value (Tables 1 and 369 Supplementary Table).

370 Impact melts do not represent a deep lunar reservoir since their origin in meteoritic 371 bombardment events occur at the lunar surface. Based on the review of Shearer et al. (2006), 372 low-Ti and high-Ti basalts make up a significantly larger component of the Moon in that they 373 cover $17 \%$ of lunar surface, but they represent just $\sim 1 \%$ of the lunar crust volume (Head, 374 1976). The largest reservoir for which we have direct samples are highland rocks, 
representing the remaining $99 \%$ of the lunar crust, that is, $\sim 10 \%$ of the volume of the Moon

376 (Papike et al., 1998). However, the present work reveals that this reservoir is more 377 heterogeneous than previously anticipated (Poitrasson et al., 2004), with a total $\delta^{57} \mathrm{Fe}$ range of $378 \sim 1.2 \%$. Subdividing these highland rocks into two groups consisting of ferroan anorthosites 379 and Mg-suite rocks makes no difference since both groups are also very heterogeneous 380 isotopically, as computed above. As discussed above, this likely stems from sample aliquot 381 allocations that are too small to produce representative $\delta^{57} \mathrm{Fe}$ analyses of bulk rocks given the 382 frequently coarse-grained nature of highland rocks. Whether calculated as a highland rock 383 group or separated as a ferroan anorthosite and $\mathrm{Mg}$-suite groups, the uncertainties of the 384 means are too high for the precision required for comparative planetology studies (i.e., $<0.1 \%$ o level; see Dauphas et al., 2009 and Poitrasson et al., 2013).

The next step is to determine whether the rock groups sampled at the surface of the Moon (i.e., low-Ti, high-Ti mare basalts, highland rocks...) are actually representative of 388 larger-scale lunar reservoirs. Liu et al. (2010) have shown that low-Ti and high-Ti mare 389 basalts do not exhibit $\mathrm{Fe}$ isotope variations as a function of magmatic differentiation. This feature has also been observed for most terrestrial igneous rocks, except for highly evolved 391 silicate compositions, such as granites and rhyolites (Poitrasson and Freydier, 2005; 392 Schoenberg and von Blanckenburg, 2006; Heimann et al., 2008; Schuessler et al., 2009; Telus 393 et al., 2012; Foden et al., 2015). Iron isotope variations in mafic rocks have been observed in 394 the closed-system Kilauea Iki lava lake, Hawaii (Teng et al., 2008), that were subsequently 395 shown to be caused by kinetic effects (Sio et al., 2013). Therefore, the question arises whether 396 or not mare basalts directly reflect the Fe isotope composition of their respective mantle 397 sources. The importance of partial melting in the Earth's mantle to generate systematic Fe 398 isotope differences in derivative melts has been debated for some time. Whereas some consider this process to play a key role (Weyer et al., 2005; Weyer and Ionov, 2007; Williams 
et al., 2005; 2009; Dauphas et al., 2009), others suggested that partial melting of pristine

401 peridotitic lithologies generates only minor $\delta^{57} \mathrm{Fe}$ variations in the basaltic melts relative to 402 their peridotitic protoliths (Beard and Johnson, 2007; Poitrasson, 2007; Zhao et al., 2010; 403 Poitrasson et al., 2013). Accordingly, using Nuclear Resonant Inelastic X-ray Scattering 404 (NRIXS) measurements of synthetic glass and associated partial melting calculations, Dauphas et al. (2014a) could explain only $\sim 1 / 3$ of the observed Fe isotopic difference between measured MORBs and their estimated bulk silicate mantle. The issue is essentially linked to their incorrect estimate of the bulk silicate mantle $\delta^{57} \mathrm{Fe}$. If, instead of chondritic $(\sim 0 \%$; 408 Dauphas et al., 2009; 2014a) a $\delta^{57} \mathrm{Fe}$ value of $\sim 0.1 \%$ is adopted for the Earth's mantle 409 (Poitrasson et al., 2004; 2013), then the discrepancy noted by Dauphas et al. (2014a) between 410 their experimental results and natural observations disappears. Hence, this issue remains 411 debated for the Earth and further experimental work is required. The putative mechanism to 412 explain Fe isotope fractionation during partial melting proposed by Dauphas et al. (2009; 413 2014a) hinges on the preferential incorporation of isotopically heavy $\mathrm{Fe}^{3+}$ in melts relative to 414 solid residuum. However, Liu et al. (2010) recognized that ferric iron does not occur in the 415 lunar mantle (Sato et al., 1973; Sato, 1976) and that experimental studies have shown the lack 416 of equilibrium $\mathrm{Fe}$ isotope fractionation between Fe metal (occurring in the lunar mantle) and 417 the prevalent $\mathrm{Fe}^{2+}$ species at mantle conditions (Roskosz et al., 2006; Poitrasson et al., 2009). 418 As a result, Liu et al. (2010) concluded that: 1) partial melting in the lunar mantle probably 419 did not produce Fe isotope fractionation, and 2) Fe isotope compositions of low-Ti and high420 Ti mare basalts directly mirror those of their corresponding lunar mantle sources. These 421 conclusions have recently been challenged by Sedaghatpour and Jacobsen (2019) on the basis 422 of a fractional crystallization model. However, these models are frequently underconstrained, 423 with many of the unknown parameters adjusted to fit the observed bulk-rock analyses (see 424 review by Dauphas et al., 2017). As a result, these models do not provide a strong constraint 
on the actual process at play to explain the observed bulk-rock isotopic compositions measured. For instance, Sedaghatpour and Jacobsen (2019) used an estimated $\Delta^{57} \mathrm{Fe}_{\text {olivine-melt }}$ fractionation factor of $-0.21 \%$ whereas it was shown experimentally to be at $\sim 0 \%$ for mafic melts, including those having the chemistry of mare basalts (Prissel et al., 2018). We thus take this as a strong support for the conclusions derived by Liu et al. (2010). Many authors have estimated the mineralogy of mantle sources of low-Ti and high-Ti 431 basalts. For example, Snyder et al. (1992) and Beard et al. (1998) inferred an important role of 432 ilmenite in the genesis of high-Ti basalts, although physical constraints of the lunar magma 433 ocean evolution must also be considered (e.g. Elkins-Tanton et al., 2011). Poitrasson (2007) 434 discussed that ilmenite, although potentially explaining elevated Ti contents of high-Ti basalts 435 (Snyder et al., 1992), would be incapable of shifting $\delta^{57} \mathrm{Fe}$ towards high values given that 436 theoretical $\log \beta$ factors (a reduced isotopic partition function factor) calculated for ilmenite 437 were among the lowest for silicate and oxide minerals (compare Figures 1 and 2 from 438 Polyakov and Mineev, 2000). As a consequence, melting of an ilmenite-rich source should 439 not result in basaltic melts with elevated $\delta^{57} \mathrm{Fe}$ values. However, more recent Fe isotope 440 analyses of mineral phases of mare basalts have shown that ilmenite is in most cases 441 isotopically heavier than coexisting pyroxene and plagioclase (Craddock et al., 2010). To 442 directly compare Fe isotope data for mineral separates with theoretical calculations, we have 443 to assume that the mineral fractions analyzed by Craddock et al. (2010) are pure and represent 444 equilibrium mineral isotope compositions. This might not be the case for all samples in their 445 study given the observed scatter in inter-mineral Fe isotopic fractionation, however. With this 446 caveat in mind, it would indicate that, similar to pyrite (Blanchard et al., 2009, 2012; 447 Polyakov et al., 2013), the Fe isotope fractionation factor for ilmenite estimated by Polyakov 448 and Mineev (2000) appears to be grossly underestimated. If correct, the heavy Fe isotope 449 signature of high-Ti mare basalts may be explained by partial melting of ilmenite in their 
source mantle as proposed by Liu et al. (2010). They based their model on the inferences from Snyder et al. (1992) and Elkins-Tanton et al. (2011) suggesting that $>78 \%$ of the early lunar magma ocean crystallized olivine and orthopyroxene, whereas an ilmenite-rich cumulate formed only after $95 \%$ lunar magma ocean crystallization. Combined with the remote sensing study of Giguere et al. (2000) indicating that high-Ti basalts should represent $\sim 10 \%$ of all lunar maria, Liu et al. (2010) estimated that only $\sim 10 \%$ of the lunar upper mantle is akin to the source of the high-Ti mare basalts, whereas the remaining is similar to the source of the low-Ti mare basalts. Given that mare basalts likely mirror the Fe isotope composition of their source (see above), we can estimate the $\delta^{57} \mathrm{Fe}$ of the lunar upper mantle at $0.142 \pm 0.026 \%$ (Fig. 2) from the newly derived mean $\delta^{57} \mathrm{Fe}$ values of low-Ti and high-Ti basalts, combined with the relative proportion of their mantle protoliths (of respectively 90 and $10 \%$, with an estimated uncertainty of $10 \%$ by Liu et al., 2010), using a simple mass balance calculation. This value would apply to the upper $\sim 250 \mathrm{~km}$ of the lunar mantle considering mare basalt petrogenesis (Longhi, 1992). The estimated size of this reservoir from seismology extends down to $500 \mathrm{~km}$, where the limit between the upper and lower lunar mantle was set (Nakamura, 1983).

It is interesting to note that lunar volcanic picritic glasses, thought to have been derived from the melting of protoliths located $360-520 \mathrm{~km}$ deep in the lunar mantle (Delano, 1979; Elkins-Tanton et al., 2003), show somewhat lighter Fe isotope signatures. However, the $\delta^{57} \mathrm{Fe}$ values scatter by over $\sim 0.5 \%$, even for the same samples (Poitrasson et al., 2004; Weyer et al., 2005; Moynier et al., 2006; Sossi and Moynier, 2017). Whether this reflects Fe isotope stratification intrinsic to the lunar mantle, an effect of volcanism through fire fountaining (Poitrasson et al., 2004; Sossi and Moynier, 2017) or a sample heterogeneity issue remains to be tested. 
The lunar highland rocks, and notably the anorthosites that make up $\sim 80 \%$ of the crust

475 (Papike et al., 1998), may potentially give a more comprehensive view of the lunar mantle composition given that it was produced by magma ocean differentiation. Estimates for depth

477 of the early lunar magma ocean may vary from 500 to $1200 \mathrm{~km}$, and up to the entire Moon, 478 depending again on whether seismic or petrological constraints are preferred (Shearer et al., 479 2006; Wieczorek et al., 2006). However, as discussed above, the majority of the highland 480 samples for which Fe isotope data exist may show a potential effect of their coarse-grained, essentially mono-mineral nature. This makes the determination of the Fe isotope composition of the bulk lunar highlands reservoir based solely on mean $\delta^{57} \mathrm{Fe}$ values of these rocks rather imprecise $(0.078 \pm 0.124 \%$; Table 1$)$ to provide useful constraints. Even if highland rocks are 484 split into ferroan anorthosites and Mg-suite rocks, the large uncertainties remaining do not change this conclusion. As a parallel to the isotopically heterogeneous Earth's mantle possibly linked to partial melting events (Williams et al., 2005; Weyer and Ionov, 2007; Williams and Bizimis, 2014), but most importantly due to metasomatic effects (Weyer et al., 2007; Zhao et al., 2010; Poitrasson et al., 2013), a more precise $\delta^{57} \mathrm{Fe}$ estimate of this reservoir can only be provided by a careful consideration of the petrology of these rocks, even though metasomatic processes are less likely for the Moon (Wang et al., 2015). It has been shown above that 491 plagioclase leads to heavy bulk-rock Fe isotope compositions whereas olivine tends towards 492 isotopically light values in case of diffusion. Besides sample aliquot representativeness issues, such kinetic effects in olivine may make the bulk rock $\delta^{57}$ Fe lighter (Collinet et al., 2017). In 494 addition, these rocks may also represent mixed lithologies (Ryder, 1982; James et al., 1991). 495 Plotting the bulk-rock $\delta^{57} \mathrm{Fe}$ versus the modal content of the other major phases from these 496 samples showing less variable Fe isotope fractionation, i.e., pyroxenes, leads to a more 497 precise Fe isotope composition for highland rocks (Fig. 3). By using samples with $>10$ modal $498 \%$ pyroxene, a better-constrained mean $\delta^{57} \mathrm{Fe}$ of $0.094 \pm 0.035 \%$ is obtained for lunar 
highlands. This value essentially corresponds to the mean of the six Mg-suite norites for which $\mathrm{Fe}$ isotope compositions are available (Supplementary Table), although three anorthosites and one Mg-suite troctolite also fall on this mean value (Fig. 3).

\subsection{Implications for the Fe isotope composition of bulk Moon}

Overall, it appears that the $\delta^{57} \mathrm{Fe}$ estimate of the lunar upper mantle sampled by mare basalts $(0.142 \pm 0.026 \%)$ is indistinguishable from the value obtained from highland rocks $(0.094 \pm 0.035 \%$; Fig. 3$)$ that likely sample a larger portion of the lunar mantle. If partial melting of the lunar mantle imparted no measurable Fe isotope fractionation (Liu et al., 2010; Sossi and Moynier, 2017), it is likely that the highland $\delta^{57} \mathrm{Fe}$ value of $0.094 \pm 0.035 \%$ is a relevant estimate of the silicate portion of the Moon, considering the mass balance of these reservoirs.

Schoenberg and von Blanckenburg (2006) and Elardo and Shahar (2017) have hypothesized that $\mathrm{Fe}$ isotope fractionation between silicate portions of terrestrial planets and their metallic cores could occur. In contrast, the investigation of Fe isotope compositions in various meteorite classes led to the conclusion that this mechanism is unlikely for planetary bodies (Poitrasson et al., 2005), an inference also supported by subsequent experimental investigations (Roskosz et al., 2006; Poitrasson et al., 2009; Hin et al., 2012). This conclusion was challenged using the three-isotope experimental approach (Shahar et al., 2015), although four out of the five more recent experimental results of Elardo et al. (2019) showed no statistically significant Fe isotope fractionation between metal and silicate. In practice, this three-isotope methodology involves, at high temperature, a first thorough chemical and isotopic mixing between the liquid metallic alloy and the silicic melt followed by "un-mixing" along a secondary fractionation line according to Shahar et al. (2017, see their Fig. 2B). As a 
result, the remainder of the system evolution until isotopic equilibrium is very similar to timeseries experiments conducted without spike in which losses are monitored by mass balance. Besides time series, the experiments of Poitrasson et al. (2009) were reversed, and the lack of Fe isotope fractionation between metal and silicate at equilibrium under planetary core formation conditions was also concluded in studies using a completely different experimental set ups (Roskosz et al., 2006; Hin et al., 2012; and see also results of Elardo et al., 2019), as well as in studies using meteorite samples (Poitrasson et al., 2005; Chernonozhkin et al., 2016, 2017; Jordan et al., 2019). Further, this three-isotope experimental methodology could also be affected by possible kinetic biases (Bourdon et al., 2018), so results obtained by this method should be interpreted with caution.

On a more theoretical side based on NRIXS measurements of high-pressure mineral phases, Polyakov (2009) proposed that a very high pressure-induced phase change in the lower mantle, at pressures above $\sim 100 \mathrm{GPa}$, may generate Fe isotope differences between the silicate Earth and metallic core. This hypothesis does not apply to the lunar core-mantle differentiation, though, given the too low pressures occurring in the lunar interior. The origin of the lunar material in the aftermath of a Moon-forming giant impact is debated (see review by Dauphas et al., 2014b), with models involving various proportions of the impactor material and the proto-Earth mantle. However, the Moon forming material is unlikely to be inherited from the silicate portion of the Earth from a giant impact occurring at a point when the Earth was already big enough to reach $100 \mathrm{GPa}$ since only a very small portion of the deep Earth mantle would show this heavy Fe isotope signature in the framework of Polyakov (2009) theory. Moreover, subsequent studies using similar NRIXS approaches did not support Polyakov (2009) inferences since they have concluded that metal-silicate at high pressure and high temperature conditions should result in undetectably small Fe isotope fractionation (Dauphas et al., 2014a; Liu et al., 2017; Yang et al., 2019). Therefore, the estimate of Fe 
isotope composition of the lunar silicate mantle also involves its small metallic core and it is

550 thus valid for the bulk Moon (Fig. 2). Collectively, at the current level of knowledge, the bulk

551 lunar $\delta^{57} \mathrm{Fe}$ composition should be close to $0.094 \pm 0.035 \%$, which is indistinguishable from 552 the Earth's value of $0.10 \pm 0.03 \%$ o (Fig. 2).

553 This lunar estimate agrees well with the recent value proposed by Sossi and Moynier 554 (2017), though on the basis of a more limited set of lunar samples (five Mg-suite rocks consisting mostly of norites) and using different lines of reasoning. It is significantly heavier

556 than the other recent estimate of Wang et al. (2015) that was based on a sole sample only 557 (dunite 72415); that particular sample has been shown to yield rather heterogeneous $\delta^{57} \mathrm{Fe}$ 558 values depending on the sample allocation (Fig. 2) and it was based on a corrected isotopic Fe 559 composition using isotopic diffusion parameters in olivine that have been revised since (Oeser 560 et al., 2015).

\subsection{Implications for the formation of the Moon}

Given the previously described experimental and theoretical disagreements noted in the

565 literature as to whether the mantle-core differentiation did generate isotopically distinct 566 silicate and metallic reservoirs in the interior of the Earth, the bulk lunar Fe isotopic 567 composition can constitute a good test of this idea. If correct, we should expect a silicate 568 Earth with a heavier Fe isotope composition than that of the silicate Moon since the high 569 pressures required for the phase transition to impart additional Fe isotope fractionation were 570 not reached in the lunar interior. Realizing that no observation supports a Moon isotopically 571 lighter than the silicate fraction of the Earth, Polyakov (2009) and Rustad and Yin (2009) 572 concluded that a Moon-forming giant impact is required to enable the Moon to acquire the 573 heavy $\mathrm{Fe}$ isotope composition of the Earth through a homogenization process such as that 
proposed by Pahlevan and Stevenson (2007). Such a scenario implies that a large fraction of

575 the Moon-forming material came from the proto-Earth mantle, which is not easy to achieve even using high resolution numerical simulations (Canup et al., 2013). Furthermore, and as

577 discussed above, another constraint to this scenario is that the giant impact should have 578 occurred sufficiently late in the proto-Earth accretion history to achieve a mantle-core 579 boundary pressure well beyond $\sim 100 \mathrm{GPa}$ pressure at which the Fe isotope metal-silicate 580 fractionation process proposed by Polyakov (2009) can operate. However, the current Earth's 581 mantle-core boundary is only $\sim 32 \mathrm{GPa}$ higher than this limit, so the proportion of mantle 582 having the phase change and associated isotopic effect proposed by Polyakov (2009) is 583 limited. Therefore, the Earth should have nearly reached its current size and enough time 584 should be allowed to lead the deep mantle to impart its Fe isotope composition to the 585 shallower portions by convection before the impact. However, it appears that terrestrial 586 mantle homogenization was not achieved 1 Ga after Earth's formation (Bennett et al., 2007; 587 Touboul et al., 2012; Debaille et al., 2013), so well after the putative Moon-forming giant 588 impact timeframe. Furthermore, the Moon forming material should essentially come from the 589 proto-Earth to make this scenario tenable, which seems unlikely (Canup et al., 2013; Dauphas 590 et al., 2014b). Hence, our best estimate for the Moon $\delta^{57} \mathrm{Fe}$ value, which is indistinguishable 591 from that of the Earth (Fig. 2), therefore also provides a constraint against terrestrial mantle592 core Fe isotope fractionation. However, whereas meteorite and experimental studies conclude the absence of Fe 594 isotope fractionation during mantle-core differentiation of planetary bodies (Poitrasson et al., 595 2005; Roskosz et al., 2006; Poitrasson et al., 2009; Hin et al., 2012; Chernonozkhin et al., 596 2016, 2017), some recent experimental studies propose an opposite sense of fractionation 597 during mantle-core differentiation, that is, with a metallic portion becoming isotopically 598 heavier (Shahar et al., 2015; Elardo and Shahar, 2017; Elardo et al., 2019). Such a sense of Fe 
isotope fractionation would yield planetary mantles isotopically lighter than chondrites. This

600 finds neither evidence from the lunar samples analyzed so far apart from the extremely

601 heterogeneous volcanic glasses (see above), nor is this supported by the latest planetary $\delta^{57} \mathrm{Fe}$

602 estimates (see Wang et al., 2012; Sossi et al., 2016; Dauphas et al., 2017).

603 A simpler scenario can explain the heavy Fe isotope composition of the Earth, Moon

604 and angrite parent body through the increased volatility of light Fe isotopes during the

605 accretion of the protoplanetary disk (Sossi et al., 2016) and/or during accretionary impacts

606 (see Poitrasson et al., 2004). Sossi et al. (2016) proposed an effect linked to differential

607 condensation of solids in the protoplanetary accretion disk on the basis of a positive

608 correlation between $\delta^{57} \mathrm{Fe}$ and $\mathrm{Fe} / \mathrm{Mn}$ estimates of planetary bodies (Fig. 4a), except

609 chondrites. However, correlations between elemental ratios of contrasted volatilities $(\mathrm{Rb} / \mathrm{Sr}$ or

$610 \mathrm{Mn} / \mathrm{Na}$ ) and $\delta^{57} \mathrm{Fe}$ would rather suggest two different histories for the Earth, the Moon and the

611 angrite parent body on one side and Mars, Vesta and the chondrite (CI) parent body on the

612 other (Fig. $4 \mathrm{~b}$ and c). Since there are no reasons to consider that Mars, Vesta and the

613 chondrite parent body chemistries were also unaffected by the effect of differential solid

614 condensation of the protoplanetary accretion disk, the dichotomy observed in Figs. $4 \mathrm{~b}$ and c

615 suggests that $\mathrm{Fe}$ isotopes record different accretion mechanisms. The lack of Fe isotope

616 variation for Mars and Vesta relative to the chondrite (CI) parent body would imply

617 accretionary processes through runaway growth, whereas the Earth, Moon and angrite parent

618 body would be additionally affected by high-energy impacts towards the end of their accretion

619 history (Poitrasson et al., 2004; Wang et al., 2012). This would produce planetary bodies

620 enriched in heavy Fe isotopes through the loss of light Fe isotopes that do not necessarily

621 require percent-level Fe loss, as computed by Poitrasson et al., (2004), potentially leading to

622 measurable Fe isotope variations. This is in contrast to the effect of differential condensation

623 in the protoplanetary accretion disk that would primarily generate changes in elemental 
abundances, potentially accompanied by Fe isotope variations (Sossi et al., 2016). According to the dynamic and thermodynamic calculation of Dauphas et al. (2015), such a loss of light isotopes to space in the aftermath of interplanetary impacts should be difficult for small parent bodies of the size of the angrite parent body. However, more recent calculations involving the track motion of Jupiter generating gas drag from recently impacted bodies make this hypothesis feasible (Hin et al., 2017), although the calculations were conducted down to bodies only having twice the size of the angrite parent body $(<500 \mathrm{~km})$. More observational constraints are thus required to refine and reconcile these models.

\subsection{Evaluation of the model with other stable isotope systems}

There has been a growing body of mass-dependent stable isotope planetary studies in the recent years that should be compared to the Fe isotope systematics to produce, as far as possible, a scenario taking into account all available observations. Humayun and Clayton (1995) failed to find $\mathrm{K}$ isotope fractionation among planetary bodies at the then-achievable levels of precision of $\pm \sim 0.5 \%$ at the $95 \%$ confidence level. Two decades later and using advanced plasma source mass spectrometry techniques, Wang and Jacobsen (2016) determined that lunar rocks are higher by $\sim 0.4 \%$ in $\delta^{41} \mathrm{~K}$ relative to terrestrial samples and chondrites. They interpreted this new observation as tracking the effect of a high-energy, high angular momentum giant impact in a thick gas atmosphere surrounding the impacted protoEarth (Lock et al., 2018) rather than a low-energy disk equilibration model (Pahlevan and Stevenson, 2007).

The stable isotope compositions of volatile elements Ga (half-mass condensation temperature $\mathrm{T}_{\mathrm{c}}$ of $968 \mathrm{~K}$, Lodders, 2003), $\mathrm{Rb}\left(\mathrm{T}_{\mathrm{c}}=800 \mathrm{~K}\right.$, Lodders, 2003) and $\mathrm{Zn}\left(\mathrm{T}_{\mathrm{c}}=726 \mathrm{~K}\right.$; Lodders, 2003) also yielded isotopically heavier values consistent with a giant impact Moon- 
649 forming scenario, associated with volatile loss (Paniello et al., 2012; Kato et al., 2015; Kato et 650 Moynier, 2017; Pringle and Moynier, 2017). However, as the database growths, the lunar 651 rocks appear to be extremely heterogeneous, notably anorthosites, yielding for example a $652 \delta^{66} \mathrm{Zn}$ range of more than $15 \%$ (Paniello et al., 2012; Kato et al., 2015). By comparing the 653 stable isotope composition of the variably volatile elements $\mathrm{K}, \mathrm{Rb}$ and $\mathrm{Zn}$, Pringle and 654 Moynier (2017) noted that there is no clear systematics between the planetary isotope 655 differences and the geochemical properties of these elements. This makes a detailed 656 discussion, besides the general idea of a volatility effect explaining the high $\delta^{41} \mathrm{~K}, \delta^{71} \mathrm{Ga}$, $657 \delta^{87} \mathrm{Rb}$ and $\delta^{66} \mathrm{Zn}$ for some lunar rocks relative to other planetary samples rather difficult. 658 Clearly, more work is needed to understand the igneous systematics of these stable isotope 659 systems, as already shown with the comparatively more studied Fe isotope systematics (see 660 above).

661 There is no consensus yet as to whether the majority of terrestrial bodies have a 662 chondritic $\delta^{26} \mathrm{Mg}$ signature (see recent review by Teng, 2017, and see also Sedaghatpour and 663 Jacobsen, 2019), or if the Earth is isotopically heavier (Wiechert and Halliday, 2007; Hin et 664 al., 2017). This partly results from analytical difficulties to determine accurate $\delta^{26} \mathrm{Mg}$ values 665 of silicate rock samples. Furthermore, lunar samples appear to yield heterogeneous $\delta^{26} \mathrm{Mg}$ 666 values, with high-Ti basalts tending towards lighter isotopic compositions according to 667 Sedaghatpour et al. (2013) and Sedaghatpour and Jacobsen (2019) whereas Wiechert and 668 Halliday (2007) found the opposite. Given these controversies, it is still difficult at this point 669 to use $\mathrm{Mg}$ isotope compositions to discuss planet formation and differentiation processes.

670 Silicon was another element that initially generated debates for analytical reasons 671 (Georg et al., 2007; Fitoussi et al., 2009). Further, magma differentiation or the nature of 672 protoliths may affect $\delta^{30} \mathrm{Si}$ values of igneous rocks (Savage et al., 2014), including on the 673 Moon (Poitrasson and Zambardi, 2015), although no difference between low-Ti and high-Ti 
674 mare basalts was observed (Armytage et al., 2012; Fitoussi and Bourdon, 2012; Zambardi et 675 al., 2013). However, most authors now agree on the relative $\delta^{30} \mathrm{Si}$ differences between 676 meteorite types. They also concur that the Earth and the Moon are isotopically 677 indistinguishable, with $\delta^{30} \mathrm{Si}$ close to $-0.29 \%$ relative to NBS-28 reference material). These 678 two bodies are also isotopically heavier than Mars, Vesta and chondrites, but lighter than 679 angrites (see recent review in Poitrasson, 2017).

680 Lithium is an element seemingly not easy to use for interplanetary comparisons as it 681 may potentially show strong $\delta^{7} \mathrm{Li}$ variations at the intra-mineral scale caused by thermal 682 diffusion or fluid circulations (see recent reviews in Tomascak et al., 2016 and Penniston683 Dorland et al., 2017). Yet resolved $\delta^{7} \mathrm{Li}$ variations were observed for low-Ti versus high-Ti 684 mare basalts (Magna et al., 2006; Seitz et al., 2006; Day et al., 2016). Low-Ti basalts, the 685 Earth's mantle (Jeffcoate et al., 2007; Magna et al., 2008; Tomascak et al., 2008; Marschall et 686 al., 2017), Mars (Magna et al., 2015) and Vesta (Magna et al., 2014) all carry broadly similar $687 \quad \delta^{7}$ Li signatures at $\sim 3-4 \%$.

Pilot studies of mass-dependent isotopic fractionations of $\delta^{\square} \mathrm{Sr}$ (Moynier et al., 2010) 689 and $\delta^{44} \mathrm{Ca}$ (Simon and DePaolo, 2010) do not seem to reveal significant planetary differences 690 either. This could be observed besides large stable isotope variations of chondritic samples 691 (Simon and DePaolo, 2010; Charlier et al., 2012) and an effect of differentiation for igneous 692 terrestrial rocks for $\delta^{\square} \operatorname{Sr}$ (Charlier et al., 2012). This effect of igneous differentiation was 693 also observed for mass-dependent $\delta^{49} \mathrm{Ti}$ and $\delta^{53} \mathrm{Cr}$ compositions on Earth, along with a 694 dichotomy between high- and low-Ti lunar basalts (Bonnand et al., 2016a; Millet et al., 2016). 695 Yet, the authors of these studies found similar Earth-Moon stable isotope compositions. More 696 recently, Sossi et al. (2018) produced more lunar sample $\delta^{53} \mathrm{Cr}$ values that led to an even more 697 scattered data set. After data filtering, they found an isotopically lighter $\mathrm{Cr}$ signature of the 698 Moon relative to the Earth, potentially reflecting volatile loss of oxygenated Cr species from 
the Moon towards the end of the lunar accretion history, at the lunar magma ocean stage.

700 Chondrites and achondrites $\delta^{53} \mathrm{Cr}$ are heterogeneous, possibly as a result of magmatic 701 differentiation for the latter (Bonnand et al., 2016b). Nevertheless, they seem to share the $702 \delta^{53} \mathrm{Cr}$ signature of the Earth overall (Schoenberg et al., 2016).

703

704

705

706

707

708

709

710

711

712

713

714

715

716

717

718

719

720

721

722

723

To summarize, only iron and silicon have so far been found to display a mass-dependent enrichment towards heavy isotope composition of the Earth-Moon system relative to other planetary bodies. Importantly, and in contrast to the other elements considered, Fe and Si are likely the most abundant elements of the Earth's core, besides Ni (e.g., Allègre et al., 2001; McDonough, 2014), even though estimates for silicon remain more uncertain (e.g., Hirose et al., 2013; Zambardi et al., 2013; Dauphas et al., 2015). As discussed above, metal-silicate partitioning during mantle core-differentiation is unlikely to be the major cause to explain the observed planetary Fe isotope compositions. Hence, it would be preferable, until proof of the contrary is provided, if all those isotopic observations were explained by a single process that some authors (Poitrasson et al., 2004; Zambardi et al., 2013) have proposed to interpret the estimated $\mathrm{Fe}$ and $\mathrm{Si}$ isotopic composition of planets: the partial planetary melting and vaporization associated with the Moon-forming giant impact. Experimental work has shown that the vaporization rate of a metal species from liquid metal is much larger compared to that of an oxide from a silicic melt (Wang et al., 1994). Therefore, at a given temperature of an interplanetary impact-induced vaporization, elemental Fe and Si evaporation from a metallic melt will be much more efficient than evaporation of respective oxides from the coexisting silicic melt, and thus more likely to leave a stable isotope imprint through the loss of lighter Fe and Si isotopes in space (Poitrasson et al., 2004; Zambardi et al., 2013). Numerical simulation of a Moon-forming giant impact tend to exclude models yielding a too Fe-rich outer disk to take into account the estimated lower bulk Fe content of the Moon relative to the Earth (Canup, 2004; Cuk and Stewart, 2012; Reufer et al., 2012; Canup et al., 2013). 
724 However, as mentioned above, the amount of $\mathrm{Fe}$ in the lunar-forming disk does not need to be high to account for the observed mass-dependent $\mathrm{Fe}$ and $\mathrm{Si}$ isotope systematics since previous quantitative estimates showed that less than $1 \%$ of iron and silicon loss from the Earth-Moon system into space is required in this context to explain their observed heavy isotopic compositions relative to other planetary bodies and chondrites (Poitrasson et al., 2004; Zambardi et al., 2013).

\section{Conclusions}

The new Fe isotope data for various lunar rocks clearly show isotopically distinct reservoirs. This is apparent from data for low-Ti and high-Ti mare basalts that have means significantly different to a degree of confidence well beyond 99\%. Partial melting in the lunar mantle and subsequent magmatic evolution of these mafic melts probably did not induce $\mathrm{Fe}$ isotope fractionation. Rather, this sharp difference in Fe isotope composition is likely due to lunar mantle sources having different mineralogical compositions, with heavy Fe isotope composition of high-Ti basalts likely reflecting the occurrence of ilmenite. The highland rocks, that include ferroan anorthosites and $\mathrm{Mg}$-suite rocks, also reveal a much larger isotopic scatter than previously found, of about $1.2 \%$. The finding of large $\delta^{57} \mathrm{Fe}$ differences among different CAPTEM aliquot allocations of the same samples suggest that the common $0.1-1 \mathrm{~g}$ sample size allocations is insufficient to produce a powder representative of these coarsegrained rocks for Fe isotope measurements. It seems that feldspars tend towards heavy $\delta^{57} \mathrm{Fe}$ whereas olivines tend towards light $\delta^{57} \mathrm{Fe}$ values, possibly as a result of diffusive processes for the latter. Excluding these effects with highland rocks having more than $10 \%$ pyroxene modal content leads to a more precise highland $\delta^{57} \mathrm{Fe}$ of $0.094 \pm 0.035 \%$. This value, which is based on six Mg-suite rocks but that is also within uncertainty reflected by three anorthosites 
and one troctolite, is indistinguishable from the mean upper lunar mantle value defined using

750 the $\mathrm{Fe}$ isotope systematics of mare basalts. It likely represents the bulk Moon $\delta^{57} \mathrm{Fe}$, which 751 also agrees within uncertainties with previous estimates for the bulk Earth.

752 Combined with literature data, this Earth-like Fe isotope composition of the Moon, 753 heavier by $\sim 0.1 \%$ o relative to chondrite parent bodies, Mars and Vesta, can be best explained 754 as fingerprinting the Moon-forming giant impact. This process alone provides the most 755 straightforward scenario to explain the observed isotopic pattern among planets, without 756 necessarily requiring a high-pressure, high-temperature metal-silicate stable isotope 757 fractionation event.

Acknowledgements - This study was made possible through three separate allocations of 761 lunar samples to CRN, FP and TM by CAPTEM. Carole Boucayrand, Jonathan Prunier and 762 Manuel Henry are thanked for maintaining the clean lab in excellent condition, as well as 763 Rémi Freydier and Jérôme Chmeleff for their efforts to have the Neptune MC-ICP-MS up 764 running. This manuscript was substantially revised and expanded following detailed 765 comments from Steve Elardo, two anonymous referees and GCA AE Munir Humayun. This 766 work was funded by a grant from the Programme National de Planétologie (PNP) of CNRS767 INSU to FP. CRN was supported by NASA grant NASA-NNX15AH76G.

\section{References}

771 Allègre, C.J., Manhès, G. and Lewin, E. (2001) Chemical composition of the Earth and the 772 volatility control on planetary genetics. Earth Planet. Sci. Lett. 185, 49-69. 
Armytage, R.M.G., Georg, R.B., Williams, H.M. and Halliday, A.N. (2012) Silicon isotopes in lunar rocks: Implications for the Moon's formation and the early history of the Earth. Geochim. Cosmochim. Acta 77, 504-514.

Beard, B.L. and Johnson, C.M. (2004) Inter-mineral Fe isotope variations in mantle-derived rocks and implications for the Fe geochemical cycle. Geochim. Cosmochim. Acta 68, $4727-4743$.

Beard, B.L. and Johnson, C.M. (2006) Comment on "Heavy iron isotope composition of granites determined by high resolution MC-ICP-MS" by F. Poitrasson and R. Freydier, Chemical Geology, volume 222, pages 132-147. Chem. Geol. 235, 201-204.

Beard, B.L. and Johnson, C.M. (2007) Comment on "Iron isotope fractionation during planetary differentiation" by S. Weyer et al., Earth Planet. Sci. Lett. V240, pages 251-264. Earth Planet. Sci. Lett. 256, 633-637.

Beard, B.L., Taylor, L.A., Scherer, E.E., Johnson, C.M. and Snyder, G.A. (1998) The source region and melting mineralogy of high-titanium and low-titanium lunar basalts deduced from Lu-Hf isotope data. Geochim. Cosmochim. Acta 62, 525-544.

Bennett, V.C., Brandon, A.D. and Nutman, A.P. (2007) Coupled Nd-142-Nd-143 isotopic evidence for Hadean mantle dynamics. Science 318, 1907-1910.

Blanchard, M., Poitrasson, F., Méheut, M., Lazzeri, M., Mauri, F. and Balan, E. (2009) Iron isotope fractionation between pyrite $\left(\mathrm{FeS}_{2}\right)$, hematite $\left(\mathrm{Fe}_{2} \mathrm{O}_{3}\right)$ and siderite $\left(\mathrm{FeCO}_{3}\right)$ : A firstprinciples density functional theory study. Geochim. Cosmochim. Acta 73, 6565-6578.

Blanchard, M., Poitrasson, F., Méheut, M., Lazzeri, M., Mauri, F. and Balan, E. (2012) Comment on "New data on equilibrium iron isotope fractionation among sulfides: Constraints on the mechanisms of sulfide formation in hydrothermal and igneous systems" by V.B. Polyakov and D.M. Soultanov. Geochim. Cosmochim. Acta 87, 356-359. 
Bonnand, P., Parkinson, I.J., Anand, M., 2016a. Mass dependent fractionation of stable chromium isotopes in mare basalts: Implications for the formation and the differentiation of the Moon. Geochimica Et Cosmochimica Acta, 175: 208-221.

800 Bonnand, P., Williams, H.M., Parkinson, I.J., Wood, B.J., Halliday, A.N., 2016b. Stable 801 chromium isotopic composition of meteorites and metal-silicate experiments: Implications 802 for fractionation during core formation. Earth and Planetary Science Letters, 435: 14-21.

803 Bourdon, B., Roskosz, M. and Hin, R.C. (2018) Isotope tracers of core formation. Earth-Sci. 804 Rev. 181, 61-81.

805 Bourdon, B., Tipper, E.T., Fitoussi, C. and Stracke, A. (2010) Chondritic Mg isotope 806 composition of the Earth. Geochim. Cosmochim. Acta 74, 5069-5083.

807 Canup, R.M., 2004. Simulations of a late lunar-forming impact. Icarus, 168(2): 433-456.

808 Canup, R.M., Barr, A.C., Crawford, D.A., 2013. Lunar-forming impacts: High-resolution 809 SPH and AMR-CTH simulations. Icarus, 222(1): 200-219.

810 Chakrabarti, R. and Jacobsen, S.B. (2010) The isotopic composition of magnesium in the 811 inner Solar System. Earth Planet. Sci. Lett. 293, 349-358.

812 Charlier, B.L.A., Nowell, G.M., Parkinson, I.J., Kelley, S.P., Pearson, D.G. and Burton, K.W. 813 (2012) High temperature strontium stable isotope behaviour in the early solar system and 814 planetary bodies. Earth Planet. Sci. Lett. 329, 31-40.

815 Chernonozhkin, S.M., Goderis, S., Costas-Rodriguez, M., Claeys, P. and Vanhaecke, F. 816 (2016) Effect of parent body evolution on equilibrium and kinetic isotope fractionation: a 817 combined $\mathrm{Ni}$ and $\mathrm{Fe}$ isotope study of iron and stony-iron meteorites. Geochim. 818 Cosmochim. Acta 186, 168-188.

819 Chernonozhkin, S.M., Weyrauch, M., Goderis, S., Oeser, M., McKibbin, S.J., Horn, I., Hecht, 820 L., Weyer, S., Claeys, P. and Vanhaecke, F. (2017) Thermal equilibration of iron meteorite 
and pallasite parent bodies recorded at the mineral scale by $\mathrm{Fe}$ and $\mathrm{Ni}$ isotope systematics.

822 Geochim. Cosmochim. Acta 217, 95-111.

823 Clayton, R.N., Hurd, J.M. and Mayeda, T.K. (1971) Oxygen isotopic compositions of Apollo

82415,16 and 17 samples, and their bearing on lunar origin and petrogenesis. Proceedings of 825 the Fourth Lunar and Planetary Science Conference 4, 1417-1420.

826 Clayton, R.N. and Mayeda, T.K. (1983) Oxygen isotopes in eucrites, shergottites, nakhlites, 827

Collinet, M., Charlier, B., Namur, O., Oeser, M., Medard, E. and Weyer, S. (2017) Crystallization history of enriched shergottites from $\mathrm{Fe}$ and $\mathrm{Mg}$ isotope fractionation in olivine megacrysts. Geochim. Cosmochim. Acta 207, 277-297.

831 Consolmagno, G.J. and Drake, M.J. (1977) Composition and evolution of the eucrite parent 832 body: Evidence from rare earth elements. Geochim. Cosmochim. Acta 41, 1271-1282.

833 Craddock, P.R. and Dauphas, N. (2011) Iron isotope compositions of reference material, 834 geostandards and chondrites. Geostandards and Geoanalytical Research 35, 101-123.

835 Craddock, P.R., Dauphas, N. and Clayton, R.N. (2010) Mineralogical control on iron isotopic 836 fractionation during lunar differentiation and magmatism, LPSC XXXXI, Houston, p. 837 1230.pdf.

838 Craddock, P.R., Warren, J.M. and Dauphas, N. (2013) Abyssal peridotites reveal the near839 chondritic Fe isotopic composition of the Earth. Earth Planet. Sci. Lett. 365, 63-76.

840 Cuk, M., Stewart, S.T., 2012. Making the Moon from a Fast-Spinning Earth: A Giant Impact $841 \quad$ Followed by Resonant Despinning. Science, 338(6110): 1047-1052.

842 Dauphas, N., Craddock, P.R., Asimow, P.D., Bennett, V.C., Nutman, A.P. and Ohnenstetter, 843 D. (2009) Iron isotopes may reveal the redox conditions of mantle melting from Archean to Present. Earth Planet. Sci. Lett. 288, 255-267. 
845 Dauphas, N., John, S.G. and Rouxel, O. (2017) Iron Isotope Systematics, in: Teng, F.Z., 846 Watkins, J., Dauphas, N. (Eds.), Non-Traditional Stable Isotopes. Mineralogical Soc Amer $847 \quad \&$ Geochemical Soc, Chantilly, pp. 415-510.

848 Dauphas, N., Poitrasson, F., Burkhardt, C., Kobayashi, H. and Kurosawa, K. (2015) Planetary 849 and meteoritic $\mathrm{Mg} / \mathrm{Si}$ and delta $\mathrm{Si}-30$ variations inherited from solar nebula chemistry. $850 \quad$ Earth Planet. Sci. Lett. 427, 236-248.

851 Dauphas, N., Burkhardt, C., Warren, P.H. and Teng, F.Z. (2014b) Geochemical arguments for 852 an Earth-like Moon-forming impactor. Philosophical Transactions of the Royal Society A-

\section{4} Mathematical, Physical \& Engineering Science 372, 20130244.

Dauphas, N., Roskosz, M., Alp, E.E., Neuville, D.R., Hu, M.Y., Sio, C.K., Tissot, F.L.H., Zhao, J., Tissandiere, L., Medard, E. and Cordier, C. (2014a) Magma redox and structural

Day, J.M.D., Qiu, L., Ash, R.D., McDonough, W.F., Teng, F.Z., Rudnick, R.L. and Taylor, controls on iron isotope variations in Earth's mantle and crust. Earth Planet. Sci. Lett. 398, L.A. (2016) Evidence for high-temperature fractionation of lithium isotopes during differentiation of the Moon. Meteoritics \& Planetary Science 51, 1046-1062.

Debaille, V., O'Neill, C., Brandon, A.D., Haenecour, P., Yin, Q.Z., Mattielli, N. and Treiman, A.H. (2013) Stagnant-lid tectonics in early Earth revealed by Nd-142 variations in late Archean rocks. Earth Planet. Sci. Lett. 373, 83-92.

Dymek, R.F., Albee, A.L. and Chodos, A.A. (1975) Comparative petrology of lunar cumulate rocks of possible primary origin: Dunite 72415, troctolite 76535, norite 78235 and anorthosite 62237, Lunar and Planetary Science Conference, 6th. LPI, Houston, pp. 301341. a result of core formation. Nat. Geosci. 10, 317-321. 
Elardo, S.M., Shahar, A., Mock, T.D. and Sio, C.K. (2019) The effect of core composition on iron isotope fractionation between planetary cores and mantles. Earth Planet. Sci. Lett. $513,124-134$

Elkins-Tanton, L.T., Burgess, S. and Yin, Q.Z. (2011) The lunar magma ocean: Reconciling the solidification process with lunar petrology and geochronology. Earth Planet. Sci. Lett. 304, 326-336.

Fitoussi, C., Bourdon, B., Kleine, T., Oberli, F. and Reynolds, B.C. (2009) Si isotope systematics of meteorites and terrestrial peridotites: implications for $\mathrm{Mg} / \mathrm{Si}$ fractionation in the solar nebula and for Si in the Earth's core. Earth Planet. Sci. Lett. 287, 77-85.

Foden, J., Sossi, P.A. and Wawryk, C.M. (2015) Fe isotopes and the contrasting petrogenesis of A-, I- and S-type granite. Lithos 212, 32-44.

Georg, R.B., Halliday, A.N., Schauble, E.A. and Reynolds, B.C. (2007) Silicon in the Earth's core. Nature 447, 1102-1106.

Giguere, T.A., Taylor, G.J., Hawke, B.R. and Lucey, P.G. (2000) The titanium contents of lunar mare basalts. Meteoritics \& Planetary Science 35, 193-200.

Head, J.W. (1976) Lunar volcanism in space and time. Reviews of Geophysics 14, 265-300.

Heimann, A., Beard, B.L. and Johnson, C.M. (2008) The role of volatile exsolution and subsolidus fluid/rock interactions in producing high $\mathrm{Fe}-56 / \mathrm{Fe}-54$ ratios in siliceous igneous rocks. Geochim. Cosmochim. Acta 72, 4379-4396.

Hin, R.C., Coath, C.D., Carter, P.J., Nimmo, F., Lai, Y.J., von Strandmann, P., Willbold, M., Leinhardt, Z.M., Walter, M.J. and Elliott, T. (2017) Magnesium isotope evidence that accretional vapour loss shapes planetary compositions. Nature 549, 511.

Hin, R.C., Schmidt, M.W. and Bourdon, B. (2012) Experimental evidence for the absence of iron isotope fractionation between metal and silicate liquids at $1 \mathrm{GPa}$ and $1250-1300^{\circ} \mathrm{C}$ and its cosmochemical consequences. Geochim. Cosmochim. Acta 93, 164-181. 
895 Hirose, K., Labrosse, S. and Hernlund, J. (2013) Composition and State of the Core. Annual 896 Review of Earth and Planetary Sciences 41, 657-691.

897 Humayun, M. and Clayton, R.N. (1995) Potassium isotope cosmochemistry: Genetic 898 implications of volatile element depletion. Geochim. Cosmochim. Acta 59, 2131-2148.

899 James, O.B., Lindstrom, M.M. and McGee, J.J. (1991) Lunar ferroan anorthosite-60025 900 petrology and chemistry of mafic lithologies. Proceedings of Lunar and Planetary Science $901 \quad 21,63-87$.

902

903

904

905

906

907

908

909

910

911

912

913

914

915

916

917

918

919

Jeffcoate, A.B., Elliott, T., Kasemann, S.A., Ionov, D., Cooper, K. and Brooker, R. (2007) Li isotope fractionation in peridotites and mafic melts. Geochim. Cosmochim. Acta 71, 202218.

Jerde, E.A., Snyder, G.A., Taylor, L.A., Liu, Y.G. and Schmitt, R.A. (1994) The origin and evolution of lunar High-Ti basalts - periodic melting of a single-source at Mare Tranquillitatis. Geochim. Cosmochim. Acta 58, 515-527.

Jordan, M.K., Tang, H.L., Kohl, I.E. and Young, E.D. (2019) Iron isotope constraints on planetesimal core formation in the early solar system. Geochim. Cosmochim. Acta 246, $461-477$.

Kato, C., Moynier, F., Valdes, M.C., Dhaliwal, J.K. and Day, J.M.D. (2015) Extensive volatile loss during formation and differentiation of the Moon. Nat. Commun. 6, 4.

Kato, C. and Moynier, F. (2017) Gallium isotopic evidence for extensive volatile loss from the Moon during its formation. Sci. Adv. 3, 5.

Liu, J., Dauphas, N., Roskosz, M., Hu, M.Y., Yang, H., Bi, W.L., Zhao, J.Y., Alp, E.E., Hu, J.Y. and Lin, J.F. (2017) Iron isotopic fractionation between silicate mantle and metallic core at high pressure. Nat. Commun. 8, 6 .

Liu, Y., Spicuzza, M.J., Craddock, P.R., Day, J.M.D., Valley, J.W., Dauphas, N. and Taylor, L.A. (2010) Oxygen and iron isotope constraints on near-surface fractionation effects and 
the composition of lunar mare basalt source regions. Geochim. Cosmochim. Acta 74, 6249-6262.

Lodders, K., 2003. Solar system abundances and condensation temperatures of the elements. Astrophysical Journal, 591(2): 1220-1247.

Lock, S.J., Stewart, S.T., Petaev, M.I., Leinhardt, Z., Mace, M.T., Jacobsen, S.B., Cuk, M., 2018. The Origin of the Moon Within a Terrestrial Synestia. Journal of Geophysical Research-Planets, 123(4): 910-951.

Longhi, J. (1992) Experimental Petrology and Petrogenesis of Mare Volcanics. Geochim. Cosmochim. Acta 56, 2235-2251.

Magna, T., Wiechert, U. and Halliday, A.N. (2006) New constraints on the lithium isotope compositions of the Moon and terrestrial planets. Earth Planet. Sci. Lett. 243, 336-353.

Magna, T., Ionov, D.A., Oberli, F. and Wiechert, U. (2008) Links between mantle metasomatism and lithium isotopes: Evidence from glass-bearing and cryptically metasomatized xenoliths from Mongolia. Earth Planet. Sci. Lett. 276, 214-222.

Magna, T., Simcikova, M. and Moynier, F. (2014) Lithium systematics in howardite-eucritediogenite meteorites: Implications for crust-mantle evolution of planetary embryos. Geochim. Cosmochim. Acta 125, 131-145.

Magna, T., Day, J.M.D., Mezger, K., Fehr, M.A., Dohmen, R., Aoudjehane, H.C. and Agee, C.B. (2015) Lithium isotope constraints on crust-mantle interactions and surface processes on Mars. Geochim. Cosmochim. Acta 162, 46-65.

Marschall, H.R., Wanless, V.D., Shimizu, N., von Strandmann, P., Elliott, T. and Monteleone, B.D. (2017) The boron and lithium isotopic composition of mid-ocean ridge basalts and the mantle. Geochim. Cosmochim. Acta 207, 102-138.

McDonough, W.F. (2014) Compositional model for the Earth's core, in: Carlson, R.W. (Ed.), The mantle and core, 2nd ed. Elsevier, Amsterdam, pp. 559-576. 
945 McSween Jr, H.Y., Taylor, L.A. and Stolper, E.M. (1979) Allan Hills 77005: A new meteorite 946 type found in Antarctica. Science 204, 1201-1203.

947 Meyer, C. (2011) Lunar sample compendium. NASA, Houston, p. $948 \quad$ http://curator.jsc.nasa.gov/lunar/compendium.cfm.

949 Miller, J.C. and Miller, J.N. (1993) Statistics for analytical chemistry, 3rd ed. Ellis Horwood, $950 \quad$ New York.

951 Millet, M.A., Dauphas, N., Greber, N.D., Burton, K.W., Dale, C.W., Debret, B., Macpherson, 952 C.G., Nowell, G.M., Williams, H.M., 2016. Titanium stable isotope investigation of 953 magmatic processes on the Earth and Moon. Earth and Planetary Science Letters, 449: $954 \quad 197-205$.

955 Molini-Velsko, C., Mayeda, T.K. and Clayton, R.N. (1986) isotopic composition of silicon in 956 meteorites. Geochim. Cosmochim. Acta 50, 2719-2726.

957 Moynier, F., Agranier, A., Hezel, D.C. and Bouvier, A. (2010) Sr stable isotope composition 958 of Earth, the Moon, Mars, Vesta and meteorites. Earth Planet. Sci. Lett. 300, 359-366.

959 Moynier, F., Albarede, F. and Herzog, G.F. (2006) Isotopic composition of zinc, copper, and 960 iron in lunar samples. Geochim. Cosmochim. Acta 70, 6103-6117.

961 Nakamura, Y. (1983) Seismic velocity structure of the lunar mantle. J. Geophys. Res. 88.

962 Neal, C.R. (2001) Interior of the Moon: The presence of garnet in the primitive deep lunar 963 mantle. J. Geophys. Res.-Planets 106, 27865-27885.

964 Neal, C.R. and Taylor, L.A. (1992) Petrogenesis of Mare Basalts - a Record of Lunar 965 Volcanism. Geochim. Cosmochim. Acta 56, 2177-2211.

966 Oeser, M., Dohmen, R., Horn, I., Schuth, S. and Weyer, S. (2015) Processes and time scales 967 of magmatic evolution as revealed by Fe-Mg chemical and isotopic zoning in natural 968 olivines. Geochim. Cosmochim. Acta 154, 130-150. 
Pahlevan, K. and Stevenson, D.J. (2007) Equilibration in the aftermath of the lunar-forming giant impact. Earth Planet. Sci. Lett. 262, 438-449.

971 Papike, J.J., Ryder, G. and Shearer, C.K. (1998) Lunar samples, in: Papike, J.J. (Ed.), 972 Planetary Materials. Mineralogical Society of America, Washington, pp. 5-1:5-234.

973 Paniello, R.C., Day, J.M.D. and Moynier, F. (2012) Zinc isotopic evidence for the origin of 974 the Moon. Nature 490, 376-380.

975 Penniston-Dorland, S., Liu, X.M. and Rudnick, R.L. (2017) Lithium Isotope Geochemistry, 976 in: Teng, F.Z., Watkins, J., Dauphas, N. (Eds.), Non-Traditional Stable Isotopes. 977 Mineralogical Soc Amer \& Geochemical Soc, Chantilly, pp. 165-217.

978 Platzner, I.T. (1997) Modern isotope ratio mass spectrometry. John Wiley \& sons, Chichester, $979514 \mathrm{p}$.

980 Poitrasson, F. (2006) On the iron isotope homogeneity level of the continental crust. Chem. 981 Geol. 235, 195-200.

982

Poitrasson, F. (2007) Does planetary differentiation really fractionate iron isotopes? Earth Planet. Sci. Lett. 256, 484-492.

985 Poitrasson, F. (2017) Silicon isotope geochemistry, in: Teng, F.Z., Watkins, J.M., Dauphas, 986 N. (Ed.), Non-traditional stable isotopes. Mineralogical Society of America, Washington, D.C., pp. 289-344.

Poitrasson, F., Delpech, G. and Grégoire, M. (2013) On the iron isotope heterogeneity of 990 lithospheric mantle xenoliths: implications for mantle metasomatism, the origin of basalts and the iron isotope composition of the Earth. Contrib. Mineral. Petrol. 165, 1243-1258.

991 Poitrasson, F. and Freydier, R. (2005) Heavy iron isotope composition of granites determined 992 by high resolution MC-ICP-MS. Chem. Geol. 222, 132-147. 
993 Poitrasson, F., Halliday, A.N., Lee, D.C., Levasseur, S. and Teutsch, N. (2004) Iron isotope 994 differences between Earth, Moon, Mars and Vesta as possible records of contrasted 995 accretion mechanisms. Earth Planet. Sci. Lett. 223, 253-266.

996 Poitrasson, F., Levasseur, S. and Teutsch, N. (2005) Significance of iron isotope mineral 997 fractionation in pallasites and iron meteorites for the core-mantle differentiation of 998 terrestrial planets. Earth Planet. Sci. Lett. 234, 151-164.

999 Poitrasson, F., Roskosz, M. and Corgne, A. (2009) No iron isotope fractionation between 1000 molten alloys and silicate melt to $2000^{\circ} \mathrm{C}$ and $7.7 \mathrm{GPa}$ : Experimental evidence and 1001 implications for planetary differentiation and accretion. Earth Planet. Sci. Lett. 278, 376$1002 \quad 385$.

1003 Poitrasson, F. and Zambardi, T. (2015) An Earth-Moon silicon isotope model to track silicic 1004 magma origins. Geochim. Cosmochim. Acta 167, 301-312.

1005 Polyakov, V.B. (2009) Equilibrium iron isotope fractionation at core-mantle boundary 1006 conditions. Science 323, 912-914.

1007 Polyakov, V.B. and Mineev, S.D. (2000) The use of Mössbauer spectroscopy in stable isotope 1008 geochemistry. Geochim. Cosmochim. Acta 64, 849-865.

1009 Polyakov, V.B., Osadchii, E.G., Chareev, D.A., Chumakov, A.I. and Sergeev, I.A. (2013) Fe 1010 beta-factors for sulfides from NRIXS synchrotron experiments, 2013 Goldschmidt 1011 Conference. Mineralogical Magazine, Prague, p. 1985.

1012 Potts, P.J. (1987) A handbook of silicate rock analysis. Blackie Academic and Professional, 1013 London, $622 \mathrm{p}$.

1014 Pringle, E.A., Moynier, F. (2017). Rubidium isotopic composition of the Earth, meteorites, 1015 and the Moon: Evidence for the origin of volatile loss during planetary accretion. Earth and 1016 Planetary Science Letters, 473: 62-70. 
1017 Prissel, K.B., Krawczynski, M.J., Nie, N.X., Dauphas, N., Couvy, H., Hu, M.Y., Alp, E.E. 1018 and Roskosz, M. (2018) Experimentally determined effects of olivine crystallization and 1019 melt titanium content on iron isotopic fractionation in planetary basalts. Geochim. $1020 \quad$ Cosmochim. Acta 238, 580-598.

1021 Reufer, A., Meier, M.M.M., Benz, W., Wieler, R. (2012). A hit-and-run giant impact $1022 \quad$ scenario. Icarus, 221(1): 296-299.

1023 Richter, F.M., Chaussidon, M., Mendybaev, R.A. and Taylor, L.A. (2016) Magnesium 1024 isotopic zoning of an olivine grain from lunar microgabbro 15555: Constraints on crystallization and cooling, LPSC XXXXVII, Houston, p. 1146.pdf.

1026 Roskosz, M., Luais, B., Watson, H.C., Toplis, M.J., Alexander, C.M.O. and Mysen, B.O. 1027 (2006) Experimental quantification of the fractionation of $\mathrm{Fe}$ isotopes during metal 1028 segregation from a silicate melt. Earth Planet. Sci. Lett. 248, 851-867.

1029 Rustad, J.R. and Yin, Q.Z. (2009) Iron isotope fractionation in the Earth's lower mantle. Nat. $1030 \quad$ Geosci. 2, 514-518.

1031 Ryder, G. (1982) Lunar anorthosite 60025, the petrogenesis of lunar anorthosites, and the 1032 composition of the Moon. Geochim. Cosmochim. Acta 46, 1591-1601.

1033 Ryder, G. (1985) Catalog of Apollo 15 rocks. Part 2. 15306-15468. NASA, Houston, pp. 3391034777.

1035 Ryder, G. and Schuraytz, B.C. (2001) Chemical variation of the large Apollo 15 olivine1036 normative mare basalt rock samples. J. Geophys. Res.-Planets 106, 1435-1451.

1037 Ryder, G. and Steele, A. (1988) Chemical dispersion among Apollo 15 olivine-normative 1038 mare basalts, Lunar and Planetary Science Conference, 18th. LPI, Houston, pp. 273-282.

1039 Sato, M. (1976) Oxygen fugacity and other thermochemical parameters of Apollo 17 high-Ti 1040 basalts and their implications on the reduction mechanism. Proceedings of the Seventh 1041 Lunar and Planetary Science Conference 7, 1323-1344. 
1042 Sato, M., Hickling, N.L. and McLane, J.E. (1973) Oxygen fugacity values of Apollo 12, 14, 1043 and 15 lunar samples and reduced state of lunar magmas. Proceedings of the Fourth Lunar 1044 and Planetary Science Conference 4, 1061-1079.

1045 Saunier, G., Poitrasson, F., Moine, B.N., Grégoire, M. and Seddiki, A. (2010) Effect of hot 1046 desert weathering on the bulk-iron isotope composition of L6 and H5 ordinary chondrites. 1047 Meteorit. Planet. Sci. 45, 195-209.

1048 Savage, P.S., Armytage, R.M.G., Georg, R.B., Halliday, A.N., 2014. High temperature silicon 1049 isotope geochemistry. Lithos, 190-191: 500-519.

1050 Savage, P.S., Georg, R.B., Armytage, R.M.G., Williams, H.M. and Halliday, A.N. (2010) 1051 Silicon isotope homogeneity in the mantle. Earth Planet. Sci. Lett. 295, 139-146.

1052 Schauble, E.A. (2004) Applying stable isotope fractionation theory to new systems, 1053 Geochemistry of Non-Traditional Stable Isotopes, pp. 65-111.

1054 Schoenberg, R. and von Blanckenburg, F. (2006) Modes of planetary-scale Fe isotope 1055 fractionation. Earth Planet. Sci. Lett. 252, 342-359.

1056 Schoenberg, R., Merdian, A., Holmden, C., Kleinhanns, I.C., Hassler, K., Wille, M. and 1057 Reitter, E. (2016) The stable Cr isotopic compositions of chondrites and silicate planetary 1058 reservoirs. Geochim. Cosmochim. Acta 183, 14-30.

1059 Schuessler, J., Schoenberg, R. and Sigmarsson, O. (2009) Iron and lithium isotope 1060 systematics of the Hekla volcano, Iceland - Evidence for Fe isotope fractionation during 1061 magma differentiation. Chem. Geol. 258, 78-91.

1062 Sedaghatpour, F. and Jacobsen, S.B. (2019) Magnesium stable isotopes support the lunar 1063 magma ocean cumulate remelting model for mare basalts. Proc. Natl. Acad. Sci. U. S. A. $1064 \quad 116,73-78$.

1065 Sedaghatpour, F., Teng, F.Z., Liu, Y., Sears, D.W.G., Taylor, L.A., 2013. Magnesium 1066 isotopic composition of the Moon. Geochimica et Cosmochimica Acta, 120: 1-16. 
1067 Seitz, H.M., Brey, G.P., Weyer, S., Durali, S., Ott, U., Munker, C., Mezger, K., 2006. Lithium

1068 isotope compositions of Martian and lunar reservoirs. Earth and Planetary Science Letters, $1069 \quad 245(1-2): 6-18$.

1070 Shahar, A., Elardo, S.M. and Macris, C.A. (2017) Equilibrium Fractionation of Non1071 traditional Stable Isotopes: an Experimental Perspective, in: Teng, F.Z., Watkins, J., 1072 Dauphas, N. (Eds.), Non-Traditional Stable Isotopes. Mineralogical Soc Amer \& 1073 Geochemical Soc, Chantilly, vol. 82, pp. 65-83.

1074 Shahar, A., Hillgren, V.J., Horan, M.F., Mesa-Garcia, J., Kaufman, L.A. and Mock, T.D. 1075 (2015) Sulfur-controlled iron isotope fractionation experiments of core formation in 1076 planetary bodies. Geochim. Cosmochim. Acta 150, 253-264.

1077 Shearer, C.K., Hess, P.C., Wieczorek, M.A., Pritchard, M.E., Parmentier, E.M., Borg, L.E., 1078 Longhi, J., Elkins-Tanton, L.T., Neal, C.R., Antonenko, I., Canup, R.M., Halliday, A.N., 1079 Grove, T.L., Hager, B.H., Lee, D.C. and Wiechert, U. (2006) Thermal and magmatic 1080 evolution of the Moon, New Views of the Moon. MSA, pp. 365-518.

1081 Simon, J.I. and DePaolo, D.J. (2010) Stable calcium isotopic composition of meteorites and 1082 rocky planets. Earth Planet. Sci. Lett. 289, 457-466.

1083 Sio, C.K.I., Dauphas, N., Teng, F.Z., Chaussidon, M., Helz, R.T. and Roskosz, M. (2013) 1084 Discerning crystal growth from diffusion profiles in zoned olivine by in situ $\mathrm{Mg}-\mathrm{Fe}$ 1085 isotopic analyses. Geochim. Cosmochim. Acta 123, 302-321.

1086 Snyder, G.A., Taylor, L.A. and Neal, C.R. (1992) A Chemical-Model for Generating the 1087 Sources of Mare Basalts - Combined Equilibrium and Fractional Crystallization of the 1088 Lunar Magmasphere. Geochim. Cosmochim. Acta 56, 3809-3823.

1089 Sossi, P.A. and Moynier, F. (2017) Chemical and isotopic kinship of iron in the Earth and 1090 Moon deduced from the lunar Mg-Suite. Earth Planet. Sci. Lett. 471, 125-135. 
1091 Sossi, P.A., Nebel, O., Anand, M. and Poitrasson, F. (2016) On the iron isotope composition 1092 of Mars and volatile depletion in the terrestrial planets. Earth Planet. Sci. Lett. 449, 360$1093 \quad 371$.

1094 Spicuzza, M.J., Day, J.M.D., Taylor, L.A. and Valley, J.W. (2007) Oxygen isotope constraints 1095 on the origin and differentiation of the Moon. Earth Planet. Sci. Lett. 253, 254-265.

1096 Taylor, L.A., Patchen, A., Mayne, R.G. and Taylor, D.H. (2004) The most reduced rock from 1097 the moon, Apollo 14 basalt 14053: Its unique features and their origin. Am. Mineral. 89, 1098 1617-1624.

1099 Telus, M., Dauphas, N., Moynier, F., Tissot, F.L.H., Teng, F.Z., Nabelek, P.I., Craddock, P.R. 1100 and Groat, L.A. (2012) Iron, zinc, magnesium and uranium isotopic fractionation during 1101 continental crust differentiation: The tale from migmatites, granitoids, and pegmatites. 1102 Geochim. Cosmochim. Acta 97, 247-265.

1103 Teng, F.Z., 2017. Magnesium Isotope Geochemistry. In: Teng, F.Z., Watkins, J., Dauphas, N.

1104 (Eds.), Non-Traditional Stable Isotopes. Reviews in Mineralogy \& Geochemistry. 1105 Mineralogical Soc Amer \& Geochemical Soc, Chantilly, pp. 219-287.

1106 Teng, F.Z., Dauphas, N. and Helz, R.T. (2008) Iron isotope fractionation during magmatic 1107 differentiation in Kilauea Iki Lava Lake. Science 320, 1620-1622.

1108 Teng, F.Z., Li, W.Y., Ke, S., Marty, B., Dauphas, N., Huang, S.C., Wu, F.Y. and Pourmand, 1109 A. (2010) Magnesium isotopic composition of the Earth and chondrites. Geochim. $1110 \quad$ Cosmochim. Acta 74, 4150-4166.

1111 Tomascak, P.B., Langmuir, C.H., le Roux, P.J. and Shirey, S.B. (2008) Lithium isotopes in 1112 global mid-ocean ridge basalts. Geochim. Cosmochim. Acta 72, 1626-1637.

1113 Tomascak, P.B., Magna, T. and Dohmen, R. (2016) Advances in Lithium isotope 1114 geochemistry. Springer Verlag, 195 p. 
1115 Torcivia, M.A. and Neal, C.R. (2017) Ferroan Anorthosite 60025: Magma ocean product -

1116 and more!, LPSC XXXXVIII, Houston, p. 1480.pdf.

1117 Torcivia, M.A. and Neal, C.R. (2018) Ferroan Anorthosite 60025: A lunar breccia, LPSC 1118 XXXXIX, Houston, p. 1331.pdf.

1119 Touboul, M., Puchtel, I.S. and Walker, R.J. (2012) W-182 Evidence for Long-Term 1120 Preservation of Early Mantle Differentiation Products. Science 335, 1065-1069.

1121 Wang, K. and Jacobsen, S.B. (2016) Potassium isotopic evidence for a high-energy giant 1122 impact origin of the Moon. Nature 538, 487.

1123 Wang, K., Jacobsen, S.B., Sedaghatpour, F., Chen, H. and Korotev, R.L. (2015) The earliest 1124 Lunar Magma Ocean differentiation recorded in Fe isotopes. Earth Planet. Sci. Lett. 430, $1125 \quad 202-208$

1126 Wang, K., Moynier, F., Dauphas, N., Barrat, J.A., Craddock, P. and Sio, C.K. (2012) Iron 1127 isotope fractionation in planetary crusts. Geochim. Cosmochim. Acta 89, 31-45.

1128 Warren, P.H. (1993) A concise compilation of petrologic information on possibly nonmare 1129 Moon rocks. Am. Mineral. 78, 360-376.

1130 Weyer, S., Anbar, A.D., Brey, G.P., Munker, C., Mezger, K. and Woodland, A.B. (2005) Iron 1131 isotope fractionation during planetary differentiation. Earth Planet. Sci. Lett. 240, 251-264.

1132 Weyer, S., Anbar, A.D., Brey, G.P., Munker, C., Mezger, K. and Woodland, A.B. (2007) Fe1133 isotope fractionation during partial melting on Earth and the current view on the Fe-isotope 1134 budgets of the planets - (reply to the comment of F. Poitrasson and to the comment of B.L. 1135 Beard and C.M. Johnson on "Iron isotope fractionation during planetary differentiation" by 1136 S. Weyer, A.D. Anbar, G.P. Brey, C. Munker, K. Mezger and A.B. Woodland). Earth $1137 \quad$ Planet. Sci. Lett. 256, 638-646.

1138 Weyer, S. and Ionov, D.A. (2007) Partial melting and melt percolation in the mantle: The 1139 message from Fe isotopes. Earth Planet. Sci. Lett. 259, 119-133. 
1140 Wiechert, U. and Halliday, A.N. (2007) Non-chondritic magnesium and the origins of the 1141 inner terrestrial planets. Earth Planet. Sci. Lett. 256, 360-371.

1142 Wieczorek, M.A., Jolliff, B.L., Khan, A., Pritchard, M.E., Weiss, B.P., Williams, J.G., Hood,

1143 L.L., Righter, K., Neal, C.R., Shearer, C.K., McCallum, I.S., Tompkins, S., Hawke, B.R., 1144 Peterson, C., Gillis, J.J. and Bussey, B. (2006) The constitution and structure of the lunar 1145 interior, New Views of the Moon. MSA, pp. 221- 364.

1146 Wiesli, R.A., Beard, B.L., Taylor, L.A. and Johnson, C.M. (2003) Space weathering processes 1147 on airless bodies: Fe isotope fractionation in the lunar regolith. Earth Planet. Sci. Lett. 216, $1148 \quad 457-465$.

1149 Williams, H.M., Peslier, A.H., McCammon, C., Halliday, A.N., Levasseur, S., Teutsch, N. 1150 and Burg, J.P. (2005) Systematic iron isotope fractionation variations in mantle rocks and 1151 minerals: The effect of partial melting and oxygen fugacity. Earth Planet. Sci. Lett. 235, $1152 \quad 435-452$.

1153 Williams, H.M., Nielsen, S.G., Renac, C., Griffin, W.L., O'Reilly, S.Y., McCammon, C.A., 1154 Pearson, N., Viljoen, F., Alt, J.C. and Halliday, A.N. (2009) Fractionation of oxygen and 1155 iron isotopes by partial melting processes: Implications for the interpretation of stable 1156 isotope signatures in mafic rocks. Earth Planet. Sci. Lett. 283, 156-166.

1157 Williams, H.M. and Bizimis, M. (2014) Iron isotope tracing of mantle heterogeneity within 1158 the source regions of oceanic basalts. Earth Planet. Sci. Lett. 404, 396-407.

1159 Yang, H., Lin, J.F., Hu, M.Y., Roskosz, M., Bi, W.L., Zhao, J.Y., Alp, E.E., Liu, J., Liu, J.C., 1160 Wentzowitch, R.M., Okuchi, T. and Dauphas, N. (2019) Iron isotopic fractionation in 1161 mineral phases from Earth's lower mantle: Did terrestrial magma ocean crystallization 1162 fractionate iron isotopes? Earth Planet. Sci. Lett. 506, 113-122. 
1163 Zambardi, T., Poitrasson, F., Corgne, A., Meheut, M., Quitte, G. and Anand, M. (2013)

1164 Silicon isotope variations in the inner solar system: Implications for planetary formation, 1165 differentiation and composition. Geochim. Cosmochim. Acta 121, 67-83.

1166 Zhao, X.M., Zhang, H.F., Zhu, X.K., Tang, S.H. and Tang, Y.J. (2010) Iron isotope variations

1167 in spinel peridotite xenoliths from North China Craton: implications for mantle 1168 metasomatism. Contrib. Mineral. Petrol. 160, 1-14.

1169 Ziegler, K., Young, E.D., Schauble, E.A. and Wasson, J.T. (2010) Metal-silicate silicon 1170 isotope fractionation in enstatite meteorites and constraints on Earth's core formation. Earth $1171 \quad$ Planet. Sci. Lett. 295, 487-496.

1172

\section{Figure captions:}

1175 Fig. 1: Initial planetary iron isotope composition $\left(\delta^{57} \mathrm{Fe}\right)$ estimates for the Earth and Moon

1176 relative to IRMM-14 compared to chondrite and achondrite meteorite groups (Poitrasson, 1177 2007). The arrows depict some more recent revisions towards putatively lighter compositions 1178 for the Earth and Moon. See text for references and discussion.

1180 Fig. 2: Iron isotope composition of bulk lunar rocks expressed in $\delta^{57}$ Fe relative to IRMM-14.

1181 The group means and 2 standard error uncertainties are reported as continuous and dashed 1182 lines/gray zones, respectively. The Earth reference value $\left(\delta^{57} \mathrm{Fe}=0.10 \pm 0.03 \%\right.$; from 1183 Poitrasson et al., 2004; 2013) is shown for comparison. Note that highland rocks have been 1184 split into anorthosites and Mg-suite rocks. Samples having extreme values or variable Fe 1185 isotope compositions on different NASA CAPTEM aliquots are labeled, besides KREEP 1186 basalt 15386. Data are from Table 1 and Supplementary Table. Iron isotope composition 1187 estimates for the Lunar Upper Mantle $(0.142 \pm 0.026 \%)$ and Bulk Moon $(0.094 \pm 0.035 \%)$ from 
1188 this work are reported at the bottom. Note that previous estimates of the Bulk Moon $\delta^{57} \mathrm{Fe}$

1189 values ranged from -0.1 to $+0.2 \%$, depending on the authors (see text and Fig. 1).

1190

1191 Fig. 3: Iron isotope composition of bulk highland lunar rocks as a function of their pyroxene

1192 modal content. At low pyroxene modal contents the Fe isotope values are scattered, possibly

1193 due to the predominance of olivine affected by diffusive effects leading to low Fe isotope

1194 values or increasing plagioclase abundance having a heavy isotope composition. At higher

1195 pyroxene modal content, though, a homogeneous Fe isotope composition emerges at

$11960.094 \pm 0.035 \%$ (2SE) for these highland rocks. Data are from Table 1, Supplementary Table

1197 and the Lunar Sample Compendium (Meyer, 2011).

1198

1199 Fig. 4: Relations between iron isotope composition estimates of planetary bodies against their

$1200 \mathrm{Fe} / \mathrm{Mn}(\mathrm{a}), \mathrm{Rb} / \mathrm{Sr}(\mathrm{b})$ and $\mathrm{Mn} / \mathrm{Na}$ (c) estimates. APB stands for Angrite Parent Body; Note that

1201 the elemental ratio estimates are for CI chondrites. See Supplementary Table for data sources. 
Table 1: New iron isotope composition of bulk lunar samples from this study, along with previously published data on the same samples

\begin{tabular}{|c|c|c|c|c|c|c|c|}
\hline & Rock type & $\begin{array}{c}\text { Rock mass } \\
\text { powdered (g) }\end{array}$ & $\delta^{57} \mathrm{Fe}(\%)$ & $2 \mathrm{SE}^{\mathrm{k}}$ & $\delta^{56} \mathrm{Fe}(\%)$ & $2 \mathrm{SE}^{\mathrm{k}}$ & $\mathrm{n}$ \\
\hline \multicolumn{8}{|c|}{ Low-Ti basalts } \\
\hline 12009,130 & Olivine vitrophyre basalt & 0.856 & 0.101 & 0.031 & 0.045 & 0.020 & 6 \\
\hline 12011,29 & Pigeonite basalt & 1.003 & 0.097 & 0.081 & 0.066 & 0.056 & 6 \\
\hline 12031,37 & Pigeonite basalt & 0.824 & 0.154 & 0.071 & 0.098 & 0.066 & 6 \\
\hline 12038,244 & Feldspathic basalt & 0.874 & 0.131 & 0.056 & 0.079 & 0.027 & 6 \\
\hline $12045,30^{\mathrm{a}}$ & Ilmenite basalt & 1.032 & 0.136 & 0.094 & 0.082 & 0.062 & 6 \\
\hline $12045,13^{b}$ & & $\sim 1$ & 0.138 & 0.078 & 0.092 & 0.052 & 3 \\
\hline 12054,6 & Ilmenite basalt & 0.740 & 0.135 & 0.078 & 0.081 & 0.054 & 6 \\
\hline 14053,237 & Group C Al-rich basalt & 0.634 & 0.070 & 0.024 & 0.038 & 0.023 & 6 \\
\hline $14053,263^{\mathrm{a}}$ & & 1.003 & 0.043 & 0.023 & 0.039 & 0.020 & 6 \\
\hline $14053^{c}$ & & $\sim 0.05$ & 0.130 & 0.030 & 0.100 & 0.030 & 4 \\
\hline $15555,988^{\mathrm{a}}$ & Olivine-normative basalt & 1.097 & 0.086 & 0.064 & 0.056 & 0.041 & 6 \\
\hline $15555,115^{b}$ & & $\sim 1$ & 0.208 & 0.058 & 0.139 & 0.038 & 9 \\
\hline $15555^{\mathrm{d}}$ & & $\sim 0.1$ & 0.044 & 0.026 & 0.029 & 0.017 & 5 \\
\hline $15555,955^{\mathrm{e}}$ & & $\sim 0.05-0.1$ & 0.104 & 0.050 & 0.073 & 0.029 & 1 \\
\hline $15555,139^{f}$ & & 0.0053 & 0.10 & 0.02 & 0.05 & 0.04 & 7 \\
\hline $15555^{\mathrm{c}}$ & & $\sim 0.05$ & 0.130 & 0.050 & 0.090 & 0.030 & 2 \\
\hline 15556,198 & Olivine-normative basalt & 0.601 & 0.117 & 0.071 & 0.061 & 0.046 & 6 \\
\hline \multicolumn{2}{|c|}{ Mean low-Ti basalts (this study) ${ }^{i}$} & & 0.113 & 0.023 & & & 9 \\
\hline \multicolumn{2}{|c|}{ Mean low-Ti basalts ${ }^{j}$} & & 0.127 & 0.012 & & & 27 \\
\hline \multicolumn{8}{|c|}{ High-Ti basalts } \\
\hline 10003,178 & Low-K Group B2 basalt & 0.856 & 0.320 & 0.071 & 0.213 & 0.047 & 6 \\
\hline $10003^{c}$ & & $\sim 0.05$ & 0.200 & 0.040 & 0.130 & 0.040 & 2 \\
\hline 10044,638 & Low-K Group B1 basalt & 0.827 & 0.354 & 0.118 & 0.235 & 0.072 & 6 \\
\hline $10049,101^{\mathrm{a}}$ & High-K Group A basalt & 1.124 & 0.167 & 0.118 & 0.114 & 0.073 & 6 \\
\hline 10057,268 & High-K Group A basalt & 0.599 & 0.189 & 0.028 & 0.158 & 0.038 & 6 \\
\hline $10057^{\mathrm{c}}$ & & $\sim 0.05$ & 0.210 & 0.060 & 0.140 & 0.050 & 2 \\
\hline 10058,250 & Low-K Group B1 basalt & 0.852 & 0.290 & 0.040 & 0.198 & 0.030 & 9 \\
\hline 10092,14 & Low-K Group B3 basalt & 0.699 & 0.327 & 0.039 & 0.212 & 0.031 & 6 \\
\hline 70135,93 & Type A basalt & 1.048 & 0.238 & 0.061 & 0.146 & 0.045 & 9 \\
\hline $70135^{c}$ & & $\sim 0.05$ & 0.220 & 0.060 & 0.150 & 0.050 & 3 \\
\hline 70315,30 & Type B1 basalt & 0.991 & 0.325 & 0.050 & 0.196 & 0.034 & 6 \\
\hline 74235,62 & Type B2 basalt & 0.595 & 0.253 & 0.086 & 0.166 & 0.053 & 6 \\
\hline 74245,34 & Type $\mathrm{C}$ basalt & 0.604 & 0.213 & 0.079 & 0.107 & 0.059 & 6 \\
\hline 74275,48 & Type C basalt & 0.820 & 0.273 & 0.081 & 0.177 & 0.040 & 6 \\
\hline $74275,240^{\mathrm{g}}$ & & 0.251 & 0.270 & 0.025 & 0.220 & 0.025 & 3 \\
\hline 78598,6 & Type A basalt & 0.622 & 0.324 & 0.039 & 0.235 & 0.037 & 6 \\
\hline Mean high-' & i basalts (this study) ${ }^{i}$ & & 0.273 & 0.039 & & & 12 \\
\hline Mean high-' & i basalts ${ }^{j}$ & & 0.274 & 0.020 & & & 25 \\
\hline \multicolumn{8}{|l|}{ KREEP } \\
\hline 15386 & KREEP basalt & 0.544 & 0.183 & 0.067 & 0.112 & 0.039 & 6 \\
\hline $15386^{\mathrm{b}}$ & & $\sim 1$ & 0.230 & 0.033 & 0.154 & 0.022 & 3 \\
\hline $15386^{d}$ & & $\sim 0.1$ & 0.210 & 0.080 & 0.140 & 0.053 & 3 \\
\hline \multicolumn{8}{|c|}{ Highland rocks } \\
\hline $15415,190^{\mathrm{a}}$ & Ferroan anorthosite & 0.998 & 0.496 & 0.057 & 0.347 & 0.113 & 6 \\
\hline $15455,306^{\mathrm{a}}$ & Mg-suite Norite (CAN clast) & 1.061 & 0.070 & 0.017 & 0.024 & 0.025 & 6 \\
\hline $15455^{\mathrm{c}}$ & & $\sim 0.05$ & 0.050 & 0.010 & 0.030 & 0.010 & 5 \\
\hline
\end{tabular}




\begin{tabular}{|c|c|c|c|c|c|c|c|}
\hline 60015,785 & Cataclastic ferroan anorthosite & 0.160 & 0.054 & 0.038 & & & 6 \\
\hline $60025,874^{\mathrm{h}}$ & Ferroan anorthosite & 0.167 & -0.393 & 0.050 & -0.276 & 0.037 & 12 \\
\hline $60025^{b}$ & & $\sim 1$ & 0.225 & 0.063 & 0.150 & 0.042 & 3 \\
\hline 62255,191 & Ferroan anorthosite & 0.139 & 0.265 & 0.119 & 0.181 & 0.088 & 3 \\
\hline $62255,134^{\mathrm{b}}$ & & $\sim 1$ & 0.176 & 0.062 & 0.118 & 0.042 & 3 \\
\hline 62275,21 & Ferroan anorthosite & 0.144 & 0.272 & 0.026 & 0.064 & 0.042 & 3 \\
\hline 67955,94 & Mg-suite noritic anorthosite & 0.166 & 0.156 & 0.049 & 0.060 & 0.114 & 6 \\
\hline $77215,258^{\mathrm{a}}$ & Mg-suite noritic & 1.043 & 0.045 & 0.051 & 0.019 & 0.029 & 6 \\
\hline $77215^{\mathrm{b}}$ & & $\sim 1$ & 0.128 & 0.024 & 0.085 & 0.016 & 5 \\
\hline $72415,82^{\mathrm{h}}$ & Mg-suite dunite & 0.127 & -0.730 & 0.062 & -0.446 & 0.085 & 12 \\
\hline $72415^{f}$ & & 0.0011 & -0.50 & 0.03 & -0.35 & 0.02 & 11 \\
\hline $72415^{c}$ & & $\sim 0.05$ & -0.600 & 0.050 & -0.400 & 0.040 & 2 \\
\hline $76335,63^{a}$ & Mg-suite troctolite & 1.012 & -0.007 & 0.062 & -0.050 & 0.122 & 4 \\
\hline \multicolumn{3}{|c|}{ Mean highland rocks (this studv) ${ }^{i}$} & 0.023 & 0.235 & & & 10 \\
\hline \multicolumn{3}{|c|}{ Mean highland rocks $^{j}$} & 0.078 & 0.124 & & & 15 \\
\hline \multicolumn{8}{|c|}{ Impact melts and breccia } \\
\hline 14310 & KREEP Basaltic impact melt & 2.027 & 0.125 & 0.130 & 0.086 & 0.069 & 6 \\
\hline $14310^{\mathrm{d}}$ & & $\sim 0.1$ & 0.153 & 0.039 & 0.102 & 0.026 & 3 \\
\hline \multicolumn{3}{|c|}{ Mean impact melts and breccia ${ }^{j}$} & 0.093 & 0.055 & & & 5 \\
\hline \multicolumn{3}{|l|}{ Mean Moon } & 0.166 & 0.032 & & & 73 \\
\hline
\end{tabular}

${ }^{a}$ New dissolution from a powder prepared in Toulouse. ${ }^{b}$ Poitrasson et al. (2004), ${ }^{c}$ Sossi and Moynier (2017), ${ }^{\mathrm{d}}$ Weyer et al. (2005), ${ }^{\mathrm{e}}$ Liu et al. (2010), ${ }^{\mathrm{f}}$ Wang et al. (2015) and ${ }^{\mathrm{g}}$ Wiesli et al. (2003). ${ }^{\mathrm{h}}$ The results presented were obtained from two separate sample aliquot dissolution and Fe purification to duplicate completely the measurements. ${ }^{\text {i }}$ When several powder aliquots have been analyzed, the mean value of the sample was used for the calculation. ${ }^{\mathrm{j}}$ See the supplementary table for the extensive compilation used to compute this mean and uncertainty. When several values are available for a given rock, the mean of all these determination was used in the calulation to avoid overweighting samples with multiple determinations. ${ }^{\mathrm{k}}$ The iron isotope composition and two standard error (2SE) uncertainties quoted are calculated from the number of analyses indicated (n) and using the Student's t-correcting factors (Platzner, 1997). 
Figure 1

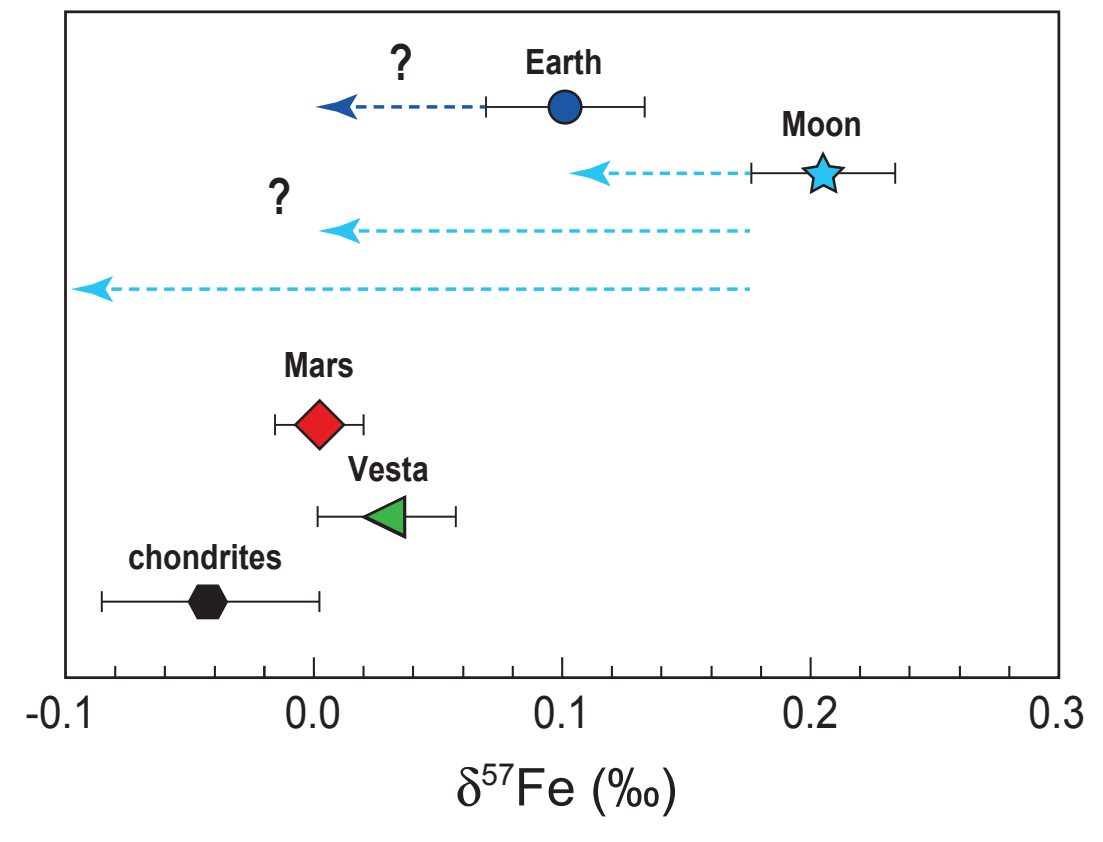

Fig. 1 


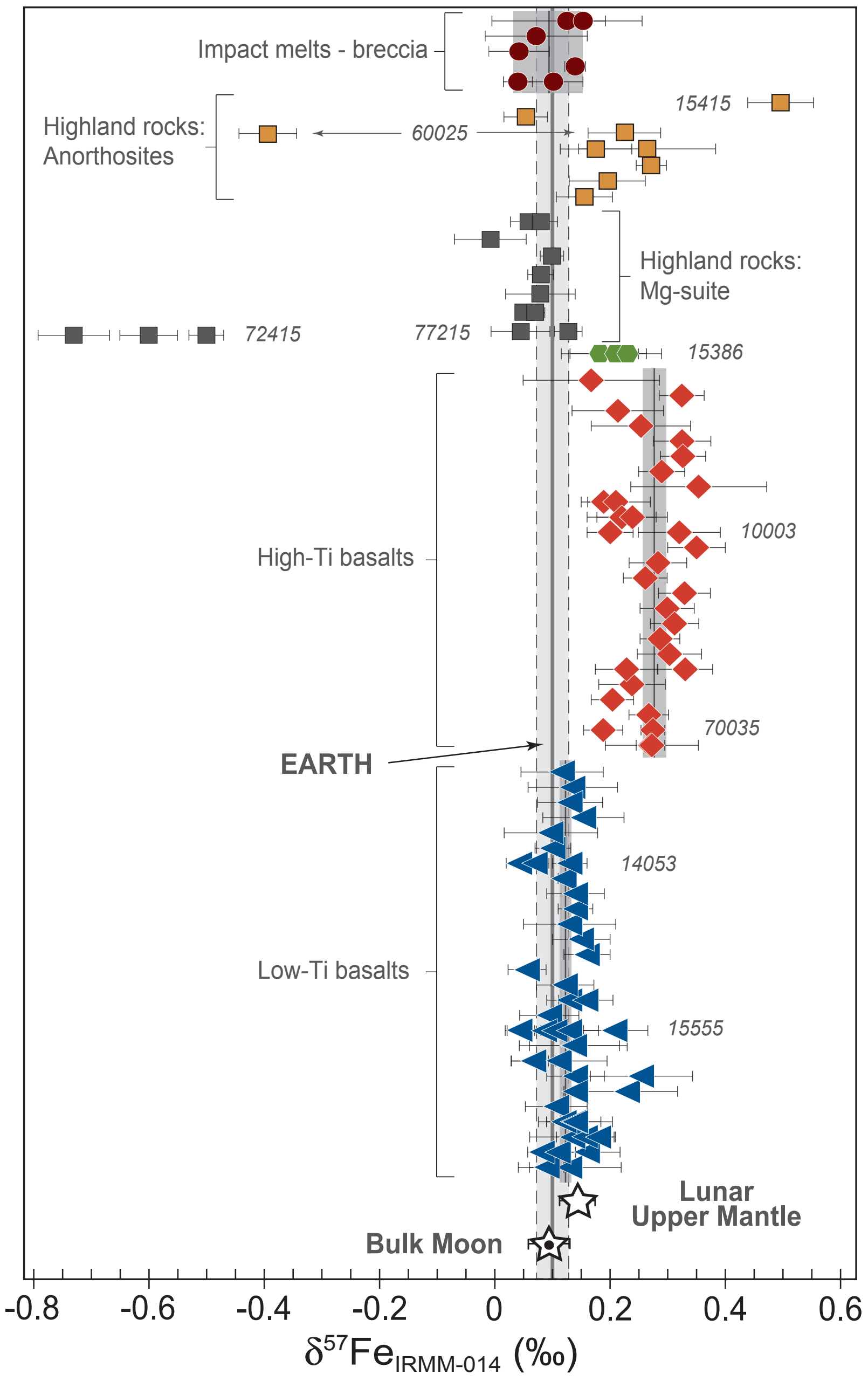

Fig. 2 
Figure 3

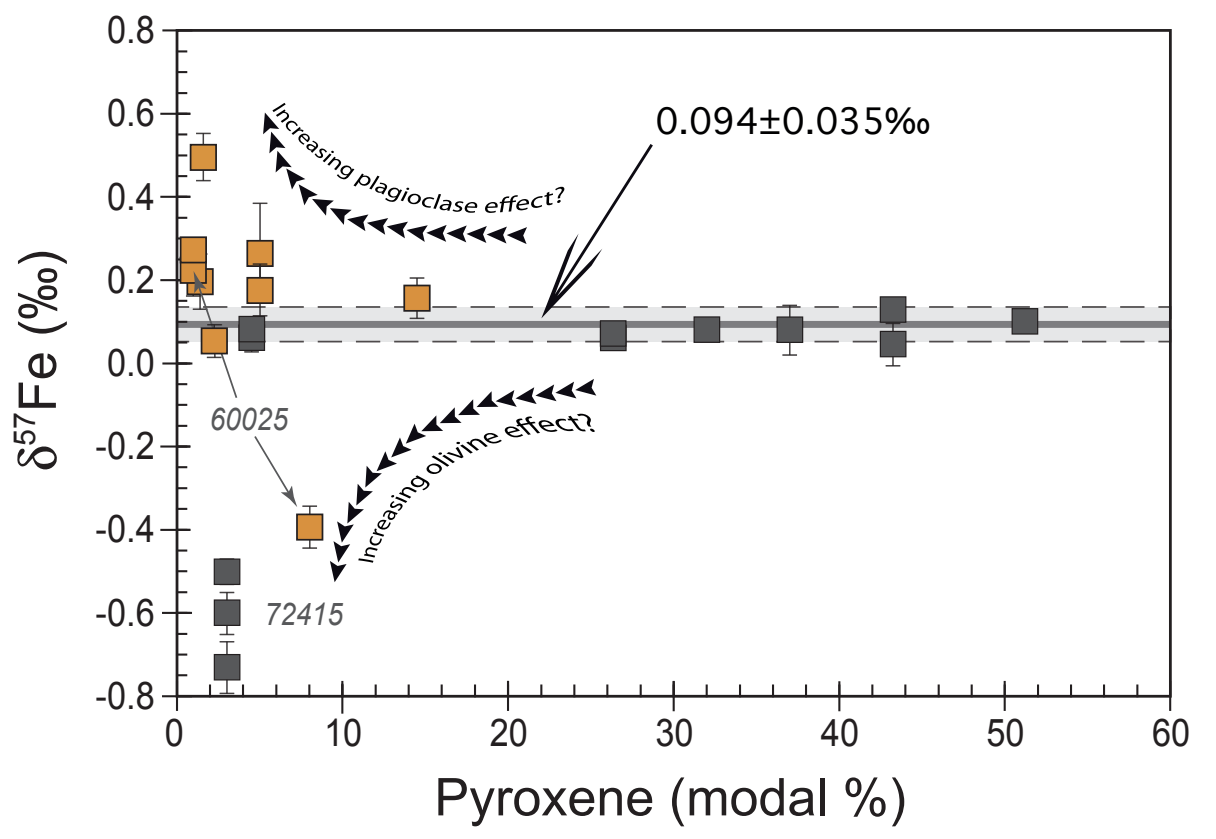

Fig. 3 

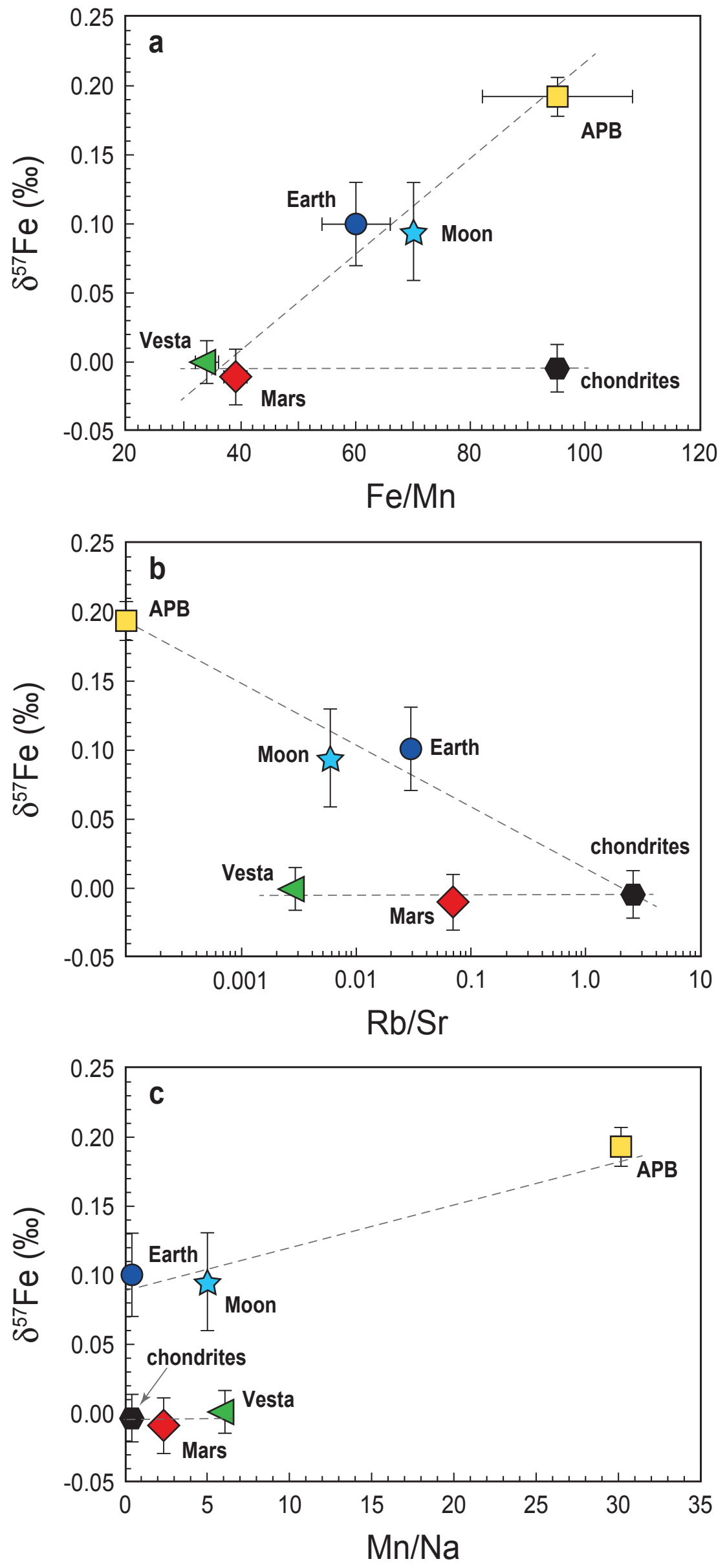

Fig. 4 
Electronic Annex
Click here to down

Electronic Annex
Click here to download Electronic Annex: Supplementary Table.xIsx

Click here to download Electronic Annex: Supplementary Table:xlsx (1)

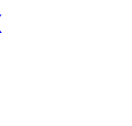

